\title{
Anticorrosive efficacy and adsorptive study of guar gum with mild steel in acidic medium
}

\author{
Anjali Peter ${ }^{1}$, Sanjay K. Sharma ${ }^{1 *}$ and Ime Bassey Obot $^{2}$
}

\begin{abstract}
Background: Gums have been found to be good corrosion inhibitors due to their functional group; they form complexes with metal ions and on the metal surfaces. Most gums have - $\mathrm{COOH}$ functional groups, which can increase the contribution of electron or charge transfer and hence facilitate inhibition through adsorption.

Methods: The corrosion and inhibition behaviors of mild steel in hydrochloric, sulphuric, and nitric acid in the presence of Cyamopsis tetragonoloba (guar gum) have been studied using the weight loss, gas chromatography mass spectrometry (GC-MS), and thermometric techniques.

Results: The temperature studies reflect that the percentage of inhibition efficiency is decreased with increase in temperature and that indicates the mechanism of physical adsorption. The calculated values of activation energy (Ea) also support the physiosorption process. The thermodynamic parameters such as heat of adsorption (Qads) and free energy of adsorption ( $\Delta$ Gads) suggested that the adsorption of inhibitor on the mild steel surface is exothermic and followed by spontaneous process.

Conclusions: The formation of an adsorbed protective film of the inhibitor molecules on the mild steel surface is confirmed by scanning electron micrographs (SEM), which proves that the guar gum acts as good inhibitor at $1 \mathrm{~N}$ acids concentration.
\end{abstract}

Keywords: Cyamopsis tetragonoloba (guar gum), Corrosion, Activation energy (Ea)

\section{Background}

Corrosion is as old as the earth itself known to people as rust; corrosion is an undesirable phenomenon which destroys the luster and beauty of the metal and lessens their life. Corrosion is the destruction and deterioration of metals as a result of reaction with environment (Fontana and Greene 1987). It is a major problem that must be confronted for safety, environmental and economic reasons in various chemical, mechanical, metallurgical, biochemical, and medical engineering applications, and more specifically in the design of a much more varied number of mechanical parts which equally vary in size, functionality, and useful lifespan (Desai 2015). One of the

\footnotetext{
* Correspondence: sk.sharmaa@outlook.com

${ }^{1}$ Green Chemistry \& Sustainability Research Group, Department of Chemistry, JECRC University, Jaipur 303905, India

Full list of author information is available at the end of the article
}

most challenging and difficult tasks is to provide the protection of metals from corrosion. Controlling these detritions of metals and alloys is a costly course of action, and industries pay out enormous amounts to manage this crisis. The controlling expense of corrosion in the developed countries such as the USA and European Union is about $3-5 \%$ of their gross national product (Bhaskaran et al. 2005). The use of corrosion inhibitors is the most reasonable and realistic way to protect metals from corrosion. Corrosion inhibitors decrease the rate of corrosion when added into the surrounding or solution of metals. They are either synthetic or natural. However, the attractiveness and use of synthetic compounds (Guendouz et al. 2013; Belfilali et al. 2012; Moreira et al. 2014; Ajmal et al. 1994; Lagrenee et al. 2002; El-Maksoud 2004; Elachouri et al. 1996; Kilmartin et al. 2002; Nishimura 1993; Kabanda and Ebenso 2012; Kabanda et al. 2012a; Kabanda et al. 2012b) 
as a corrosion inhibitor is losing ground because of their noxious and hazardous effects on mankind. Therefore, necessities occur to build up a different category of corrosion inhibitors with low poisonous effect, environment friendly and effective efficiency. This new general approach, called green chemistry, was declared which aims for the reduction and replacement of hazardous materials in order to protect the environment and people. Plants have been used by human beings for their basic needs and seem to be a promising source of cheap and harmless corrosion inhibitors. The oldest uses of plants were reported as corrosion inhibitor of Chelidonium majus (celandine) and other plants in 1930s (Raja and Sethuraman 2008). After this discovery, natural products drag the attention of scientists around the world for the research on plant extracts for corrosion inhibition. Among others, considered substances are gums, animal proteins, herbs, and even fruit peals (Africa 2008; Al-Otaibi et al. 2014; Oguzie 2006; Abdel-Gaber et al. 2009; Oguzie 2007; Kliškić et al. 2000; Benabdellah et al. 2006; Abiola et al. 2007; Raja and Sethuraman 2009; El-Etre et al. 2005). Gums have been found to be good corrosion inhibitors due to their functional group; they form complexes with metal ions and on the metal surfaces. Most gums have $-\mathrm{COOH}$ functional groups, which can increase the contribution of electron or charge transfer and hence facilitate inhibition through adsorption. Literature on the use of gums as corrosion inhibitors is very little (Eddy et al. 2013; Abdallah 2004; Umoren et al. 2008; Ameh et al. 2012). Guar gum drags special attention because of its safe use and high molecular size. The gas chromatography mass spectroscopy (GCMS) spectra of the gum show the presence of heteroatoms. Gum metal complexes occupy a large surface area, thereby blanketing the surface and shielding the metal from corrosive agents present in the solution. The presence of arbinogalactan, sucrose, oligosaccharides, polysaccharides, and glucoprotein confirms the presence of compounds containing oxygen and nitrogen atoms there, which are the active centers of adsorption (Gardner and Eikerts 1983; Bumgartner et al. 1983; Shah and Walters 1984; Peter et al. 2015).

Even though lots of plants have been reported as anticorrosive agents, still a huge kingdom of plants have not yet been appropriately considered for their anticorrosive activity. As a result, huge possibilities exist to find out green corrosion inhibitors. In persistence of our program for the corrosion inhibitor with high value and efficiency, the present paper explore the use of guar gum as effective corrosion inhibitor for mild steel corrosion in $1 \mathrm{~N} \mathrm{HCl}, \mathrm{H}_{2} \mathrm{SO}_{4}$, and $\mathrm{HNO}_{3}$ solutions using weight loss method. The effect at 304 and $313 \mathrm{~K}$ temperature on corrosion and corrosion rate process are briefly discussed with adsorption isotherm and temperature measurements.

\section{Methods \\ Materials}

Chemical composition of the tested materials, namely pure mild steel is as following (wt\%): $0.23 \% \mathrm{C}, 1.50 \% \mathrm{Mn}, 0.04 \%$ S, $0.04 \%$ P, $0.02 \% \mathrm{Al}, 0.40 \% \mathrm{Si}$, and bal Fe. The mild steel specimens were prepared by cutting mild steel sheet into rectangular-shaped pieces having dimension $3 \mathrm{~cm} \times 2 \mathrm{~cm} \times$ $0.2 \mathrm{~cm}$ containing a small hole of about $0.10 \mathrm{~mm}$ diameter near the upper edge. Specimens were polished to mirror finish by using emery paper, washed by distilled water, degreased with acetone, and put it to become dried in a moisture-free desiccators before their use in corrosion studies (Obot et al. 2010).

\section{Solutions}

The solutions of $1 \mathrm{~N} \mathrm{HCl,} \mathrm{H}_{2} \mathrm{SO}_{4}$, and $\mathrm{HNO}_{3}$ were prepared by dilution of analytical grade acids with distilled water. Gum of guar was obtained by distillation of the seed extract of guar gum plant. After drying, it is available in a form of a powder. We dissolved it in distilled water for subsequent use. We prepared the different concentrations of inhibitor (250, 500, 750, $100 \mathrm{ppm}$ ) solutions of guar gum and left it for $24 \mathrm{~h}$ to procure dissolved properly in distilled water.

\section{Quantitative measurements (weight loss method)}

Weight loss method is the most acceptable method for inhibition efficiency measurement (Obot et al. 2009). This method is considered as a baseline for the assessment in many corrosion monitoring programs (Obot and Obi-Egbedi 2010). For the experiment, a set of beakers with immersion capacity of $250 \mathrm{ml}$ were filled with $100 \mathrm{ml}$ test solution of acid $1 \mathrm{~N} \mathrm{HCl}, \mathrm{H}_{2} \mathrm{SO}_{4}$, and $\mathrm{HNO}_{3}$ concentration. Keeping one beaker aside, different concentrations $(250,500,750,100 \mathrm{ppm})$ of guar gum were added to the others at $304 \mathrm{~K}$ temperature with appropriate arrangements. Metal plates of defined dimensions $(3 \mathrm{~cm} \times 2 \mathrm{~cm} \times 0.2 \mathrm{~cm}$ ) were polished, weighed, and placed in each beaker. At 6, 24, 48, and $72 \mathrm{~h}$ intervals, the metal plates were taken out from the solution, washed with water, dried, and weighed. To observe the atmospheric corrosion course of action, the test coupons were removed from reactors for the period of the exposures for weighing with above prescribed intervals. In order to get more precise results, experiments were carried out in triplets. By this weight loss method, weight of corroded material is measured by subtraction of the final weight from the initial weight.

When this value is obtained, the inhibition efficiency (IE) can be calculated.

(W is the weight loss with (i) or without (0) influence of the inhibitor) 


$$
\mathrm{IE} \%=\frac{w_{0}-w_{i}}{w_{0}} \times 100
$$

As well as the corrosion rate $(\mathrm{CR})$ in millimeters per year was achieved by dividing the weight loss by the surface area, density, and time in hours.

$$
\mathrm{CR}=\frac{\text { weight loss }}{\text { Area } \times \text { Time } \times \text { density }} \times 8.76 \times 10^{4}
$$

where weight loss is expressed in grams, area expressed in square centimeter, time in hours, metal density in gram per cubic centimeter, and $8.76 \times 10^{4}$ is a conversion factor (Baboian 1995).

\section{GC-MS study}

GC-MS analysis was carried out on a GC clarus 500 Perkin Elmer system comprising an AOC-20i auto sampler and gas chromatograph interfaced to a mass spectrometer (GCMS) instrument. The chromatogram of compounds which were reported in GCMS of guar gum are the following: sucrose, 9,9-Dimethoxybicyclo[3.3.1]nona-2,4-dione, cetene, d-Gala-l-ido-octonic amide, 8-Pentadecanone, E-14Hexadecenal, 11,14-Eicosadienoic acid, methyl ester, decanamide, N-(2-hydroxyethyl), hexadecanoic acid, 2hydroxy-1-(hydroxymethyl, octadecanoic acid, 2-hydroxy1,3-propanediyl, cyclohexanone, 2-pentyl, 8-methyl-6nonenamide, Bis(2-(dimethylamino)ethyl) ether, 9,12Octadecadienoyl chloride, (Z,Z)-, Linalol oxide, trimethylsilyl ether, heptacosane, 1,2-15,16-diepoxyhexadecane, oxalic acid, dodecyl 3,5-difluorophenyl ester, and 12- hydroxy-3-keto-bisnor-4-cholenic acid. Interpretation on mass spectrum GC-MS was conducted using the database of National Institute Standard and Technology (NIST) having more than 62,000 patterns. The spectrum of the unknown component was compared with the spectrum of the known components stored in the NIST library.

\section{Surface analysis}

Morphological studies of the mild steel surface were undertaken by SEM examination using Nova NanoSEM 450 BRUKER scanning electron microscope from Malaviya National Institute of Technology, MNIT (Jaipur).

\section{Results and discussion}

Gravimetric measurements

All the weight loss data, together with the mass increase and metal slaughter values, are provided to make possible quantitative comparisons of the manipulation of the different environmental factors on the atmospheric corrosion of the mild steel. Mass increase is a suitable path to calculate average corrosion assault if the corrosion product composition is known.

Tables 1 and 2 show the comparative data of average metal loss, corrosion rate, and inhibition efficiency of the corroded samples at different temperature and immersion intervals. Weight loss of mild steel have found to decrease with increase in the concentration of guar gum at 303 and $313 \mathrm{~K}$ temperature for $\mathrm{HCl}$ and $\mathrm{H}_{2} \mathrm{SO}_{4}$ medium, but in $\mathrm{HNO}_{3}$ medium, we have noticed a good inhibition at $250 \mathrm{ppm}$ only that means due to hyper oxidative nature of

Table 1 Corrosion parameters of guar gum at $304 \mathrm{~K}$ temperature in different acidic medium with mild steel at different immersion

\begin{tabular}{|c|c|c|c|c|c|c|c|c|c|c|c|c|c|}
\hline \multirow[t]{3}{*}{ Medium } & \multirow{3}{*}{$\begin{array}{l}\text { Inhibitor } \\
\text { conc. }\end{array}$} & \multicolumn{3}{|l|}{$6 \mathrm{~h}$} & \multicolumn{3}{|l|}{$24 \mathrm{~h}$} & \multicolumn{3}{|l|}{$48 \mathrm{~h}$} & \multicolumn{3}{|l|}{$72 \mathrm{~h}$} \\
\hline & & Wt.loss & $C R$ & $\mathrm{IE} \%$ & Wt.loss & $C R$ & $\mathrm{IE} \%$ & Wt.loss & $C R$ & $\mathrm{IE} \%$ & Wt.loss & $C R$ & $\mathrm{IE} \%$ \\
\hline & & (gm) & $(\mathrm{mm} / \mathrm{yr})$ & & (gm) & $(\mathrm{mm} / \mathrm{yr})$ & & (gm) & $(\mathrm{mm} / \mathrm{yr})$ & & (gm) & $(\mathrm{mm} / \mathrm{yr})$ & \\
\hline \multirow[t]{5}{*}{$1 \mathrm{~N} \mathrm{HCl}$} & 0 & 0.145 & 1.92 & - & 0.518 & 6.8867 & - & 0.957 & 12.71 & - & 1.727 & 22.944 & - \\
\hline & 250 & 0.046 & 0.606 & 68.46 & 0.097 & 1.2881 & 81.295 & 0.145 & 1.9197 & 84.896 & 0.319 & 4.244 & 81.503 \\
\hline & 500 & 0.040 & 0.536 & 72.07 & 0.094 & 1.252 & 81.819 & 0.134 & 1.7745 & 86.038 & 0.243 & 3.226 & 85.94 \\
\hline & 750 & 0.036 & 0.484 & 74.82 & 0.079 & 1.0478 & 84.785 & 0.123 & 1.6283 & 87.189 & 0.208 & 2.7634 & 87.956 \\
\hline & 1000 & 0.041 & 0.549 & 71.41 & 0.073 & 0.974 & 85.857 & 0.104 & 1.3843 & 89.108 & 0.163 & 2.1652 & 90.56 \\
\hline \multirow[t]{5}{*}{$1 \mathrm{~N} \mathrm{H}_{2} \mathrm{SO}_{4}$} & 0 & 0.220 & 29.17 & - & 0.808 & 107.38 & - & 1.991 & 264.45 & - & 2.678 & 355.72 & - \\
\hline & 250 & 0.048 & 6.409 & 78.03 & 0.165 & 21.954 & 79.555 & 0.509 & 67.56 & 74.453 & 0.945 & 125.59 & 64.695 \\
\hline & 500 & 0.045 & 5.924 & 79.69 & 0.141 & 18.724 & 82.563 & 0.458 & 60.91 & 76.967 & 0.854 & 113.47 & 68.101 \\
\hline & 750 & 0.033 & 4.415 & 84.86 & 0.120 & 15.971 & 85.127 & 0.372 & 49.432 & 81.307 & 0.670 & 88.943 & 74.996 \\
\hline & 1000 & 0.030 & 4.024 & 86.21 & 0.102 & 13.516 & 87.41 & 0.324 & 42.979 & 83.747 & 0.496 & 65.859 & 81.485 \\
\hline \multirow[t]{5}{*}{$1 \mathrm{~N} \mathrm{HNO}_{3}$} & 0 & 0.882 & 117.1 & - & 1.537 & 204.14 & - & 1.212 & 160.98 & - & 1.121 & 148.86 & - \\
\hline & 250 & 0.305 & 40.53 & 65.4 & 0.405 & 53.748 & 73.67 & 0.720 & 95.64 & 40.588 & 0.729 & 96.826 & 34.954 \\
\hline & 500 & 0.333 & 44.17 & 62.29 & 0.59 & 78.393 & 61.6 & 0.875 & 116.24 & 27.789 & 0.905 & 120.24 & 19.224 \\
\hline & 750 & 0.399 & 53.06 & 54.7 & 0.771 & 102.49 & 49.8 & 0.929 & 123.36 & 23.368 & 0.918 & 121.92 & 18.099 \\
\hline & 1000 & 0.427 & 56.7 & 51.6 & 0.818 & 108.68 & 46.76 & 0.937 & 124.41 & 22.714 & 0.943 & 125.25 & 15.858 \\
\hline
\end{tabular}
time periods 
Table 2 Corrosion parameters of guar gum at $313 \mathrm{~K}$ temperature in different acidic medium with mild steel at different immersion time periods

\begin{tabular}{|c|c|c|c|c|c|c|c|c|c|c|c|c|c|}
\hline \multirow[t]{2}{*}{ Medium } & \multirow{2}{*}{$\begin{array}{l}\text { Inhibitor } \\
\text { conc. }\end{array}$} & \multicolumn{3}{|l|}{$6 \mathrm{~h}$} & \multicolumn{3}{|l|}{$24 \mathrm{~h}$} & \multicolumn{3}{|l|}{$48 \mathrm{~h}$} & \multicolumn{3}{|l|}{$72 \mathrm{~h}$} \\
\hline & & $\begin{array}{l}\text { Wt.loss } \\
\text { (gm) }\end{array}$ & $\begin{array}{l}\text { CR } \\
(\mathrm{mm} / \mathrm{yr})\end{array}$ & IE\% & $\begin{array}{l}\text { Wt.loss } \\
\text { (gm) }\end{array}$ & $\begin{array}{l}\mathrm{CR} \\
(\mathrm{mm} / \mathrm{yr})\end{array}$ & $\mathrm{IE} \%$ & $\begin{array}{l}\text { Wt.loss } \\
\text { (gm) }\end{array}$ & $\begin{array}{l}\text { CR } \\
(\mathrm{mm} / \mathrm{yr})\end{array}$ & $\mathrm{IE} \%$ & $\begin{array}{l}\text { Wt.loss } \\
\text { (gm) }\end{array}$ & $\begin{array}{l}\mathrm{CR} \\
(\mathrm{mm} / \mathrm{yr})\end{array}$ & IE\% \\
\hline \multirow[t]{5}{*}{$1 \mathrm{~N} \mathrm{HCl}$} & 0 & 0.161 & 2.134 & - & 0.536 & 7.118 & - & 0.967 & 12.842 & - & 1.754 & 23.304 & - \\
\hline & 250 & 0.052 & 0.693 & 67.52 & 0.103 & 1.3726 & 80.717 & 0.167 & 2.2245 & 82.679 & 0.339 & 4.5021 & 80.681 \\
\hline & 500 & 0.047 & 0.621 & 70.9 & 0.101 & 1.345 & 81.105 & 0.140 & 1.8638 & 85.487 & 0.264 & 3.5061 & 84.955 \\
\hline & 750 & 0.047 & 0.619 & 71 & 0.089 & 1.1784 & 83.445 & 0.129 & 1.7133 & 86.659 & 0.215 & 2.853 & 87.758 \\
\hline & 1000 & 0.045 & 0.592 & 72.28 & 0.083 & 1.1031 & 84.502 & 0.117 & 1.5541 & 87.899 & 0.182 & 2.4245 & 89.6 \\
\hline \multirow[t]{5}{*}{$1 \mathrm{~N} \mathrm{H}_{2} \mathrm{SO}_{4}$} & 0 & 0.243 & 32.26 & - & 0.841 & 111.78 & - & 2.023 & 268.75 & - & 2.724 & 361.84 & - \\
\hline & 250 & 0.058 & 7.733 & 76.03 & 0.192 & 25.526 & 77.163 & 0.639 & 84.917 & 68.403 & 1.084 & 144.04 & 60.193 \\
\hline & 500 & 0.054 & 7.203 & 77.67 & 0.176 & 23.327 & 79.131 & 0.531 & 70.582 & 73.737 & 0.966 & 128.33 & 64.534 \\
\hline & 750 & 0.043 & 5.724 & 82.25 & 0.138 & 18.344 & 83.589 & 0.471 & 62.58 & 76.715 & 0.800 & 106.24 & 70.638 \\
\hline & 1000 & 0.037 & 4.906 & 84.79 & 0.130 & 17.282 & 84.54 & 0.418 & 55.567 & 79.324 & 0.714 & 94.8 & 73.8 \\
\hline \multirow[t]{5}{*}{$1 \mathrm{~N} \mathrm{HNO}_{3}$} & 0 & 0.882 & 117.1 & - & 1.537 & 204.14 & - & 1.212 & 160.98 & - & 1.121 & 148.86 & - \\
\hline & 250 & 0.305 & 40.53 & 62.73 & 0.405 & 53.748 & 71.63 & 0.929 & 123.36 & 38.454 & 0.729 & 96.826 & 31.651 \\
\hline & 500 & 0.333 & 44.17 & 60.74 & 0.59 & 78.393 & 59.82 & 0.937 & 124.41 & 25.902 & 0.905 & 120.24 & 17.326 \\
\hline & 750 & 0.399 & 53.06 & 50.9 & 0.771 & 102.49 & 48.526 & 0.875 & 116.24 & 21.663 & 0.918 & 121.92 & 15.733 \\
\hline & 1000 & 0.427 & 56.7 & 48.6 & 0.818 & 108.68 & 44.468 & 0.823 & 109.33 & 19.805 & 0.943 & 125.25 & 13.253 \\
\hline
\end{tabular}

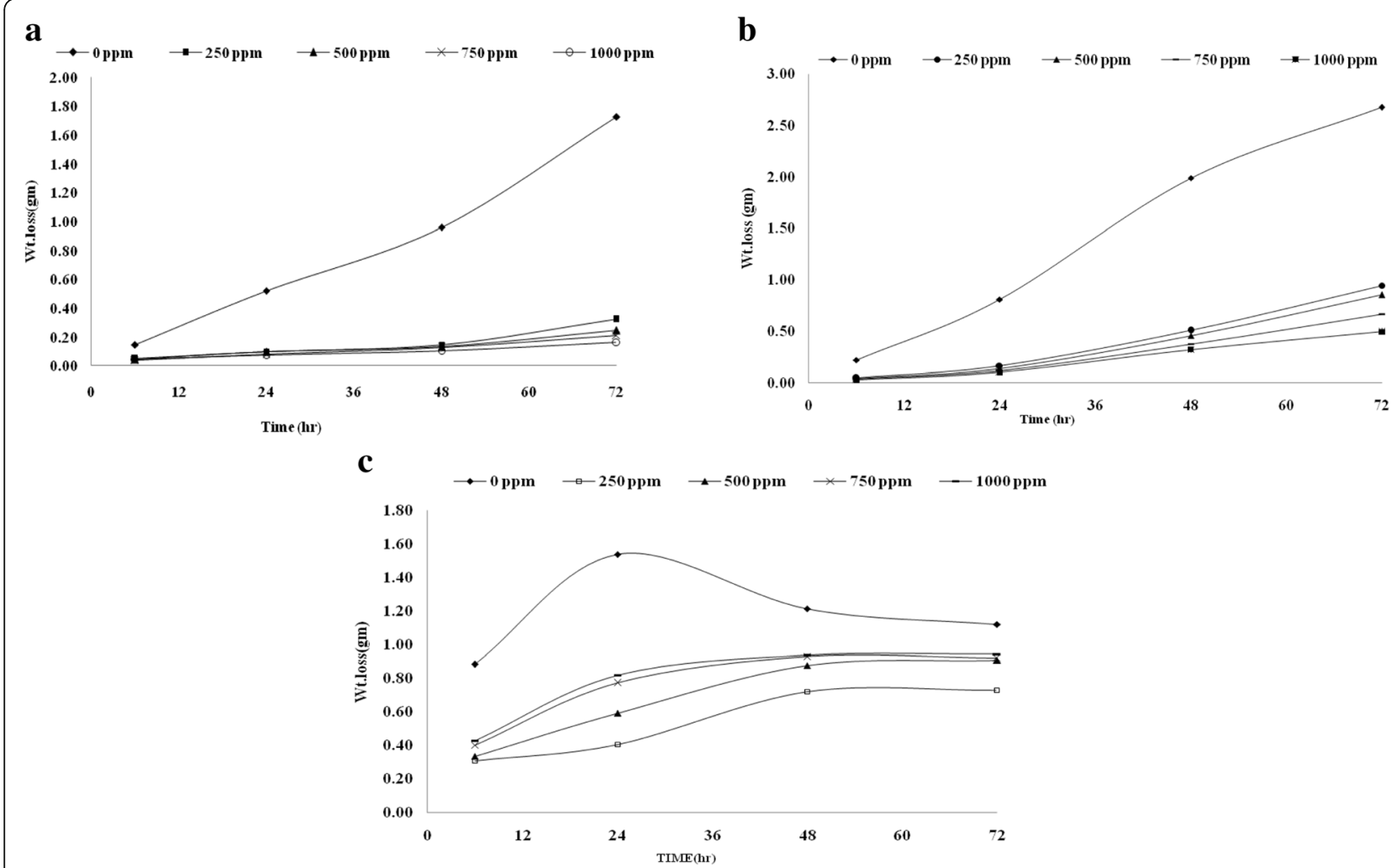

Fig. 1 Weight loss graphs of MS with different concentration of guar gum in a $1 \mathrm{~N} \mathrm{HCl}$, b $1 \mathrm{~N} \mathrm{H}_{2} \mathrm{SO}_{4}$, and $\mathbf{c} 1 \mathrm{~N} \mathrm{HNO}_{30}$ 
$\mathrm{HNO}_{3}$ acid the inhibition no longer exits. The weight loss of mild steel in the blank solution reported to be higher than comparison with the solutions of $\mathrm{HCl}, \mathrm{H}_{2} \mathrm{SO}_{4}$, and $\mathrm{HNO}_{3}$ containing a range of concentrations of guar gum. This is a sign that guar gum is an adsorption inhibitor for the corrosion of mild steel in different acids. The assessment between Tables 1 and 2 also discovered that weight loss of mild steel also increase with increasing (313 K) temperature indicating that inhibition efficiency decrease with increase in temperature. Figure 1 comparatively indicates a weight loss of mild steel in [A] $1 \mathrm{~N} \mathrm{HCl},[\mathrm{B}] \mathrm{H}_{2} \mathrm{SO}_{4}$, and $[\mathrm{C}] \mathrm{HNO}_{3}$ medium with different guar gum concentration at different times. In Fig. 2, the fall in corrosion rate has been observed with the respect of increasing inhibitor concentrations. The result clearly showed that the inhibition mechanism involves blocking of mild steel surface by inhibitor molecules via adsorption. In Fig. 3, exhibits the increase in Inhibition efficiency with increasing concentrations of the inhibitor. The maximum efficiency (90.56\%) has been observed at highest inhibitor concentration $1000 \mathrm{ppm}$ at $72 \mathrm{~h}$ at temperature $304 \mathrm{~K}$ in $1 \mathrm{~N} \mathrm{HCL}$, $87.4 \%$ for $24 \mathrm{~h}$ on $1000 \mathrm{ppm}$ in $1 \mathrm{~N} \mathrm{H}_{2} \mathrm{SO}_{4}$, and $73.67 \%$ for $24 \mathrm{~h}$ on $250 \mathrm{ppm}$ in $1 \mathrm{~N} \mathrm{HNO}_{3}$ medium. The worth of inhibition falling with high temperature represents physical adsorption mechanism (Eddy et al. 2013). According to finding results, we assume that the adsorption of foremost active elements consist in the inhibitor guard the metal surface at $304 \mathrm{~K}$ temperature (Petchiammal et al. 2012). On the other hand, it gets loosen from the metal surface with increase in temperature (313 K).

\section{Kinetic study}

A chemical reaction involves breaking of bonds in reacting molecules and formation of new bonds in product molecules. The natures of bonds are different in different substances, and rates of chemical reaction differ a lot from one another. The rate of reaction depends upon structural and energetic factors (Puri et al. 1997).

The kinetics of mild steel corrosion has investigated by drawing the graph between -log (weight loss) and time as given by the following equation (Abdel-Gaber et al. 2006a; Abdel-Gaber et al. 2006b)

$$
-\log (\text { weight loss })=\frac{\mathrm{k} 1 \mathrm{t}}{2.303}
$$

where $\mathrm{k} 1$ is the first-order rate constant and $t$ is the time in hours. Figures 4 and 5 show kinetic plots for the

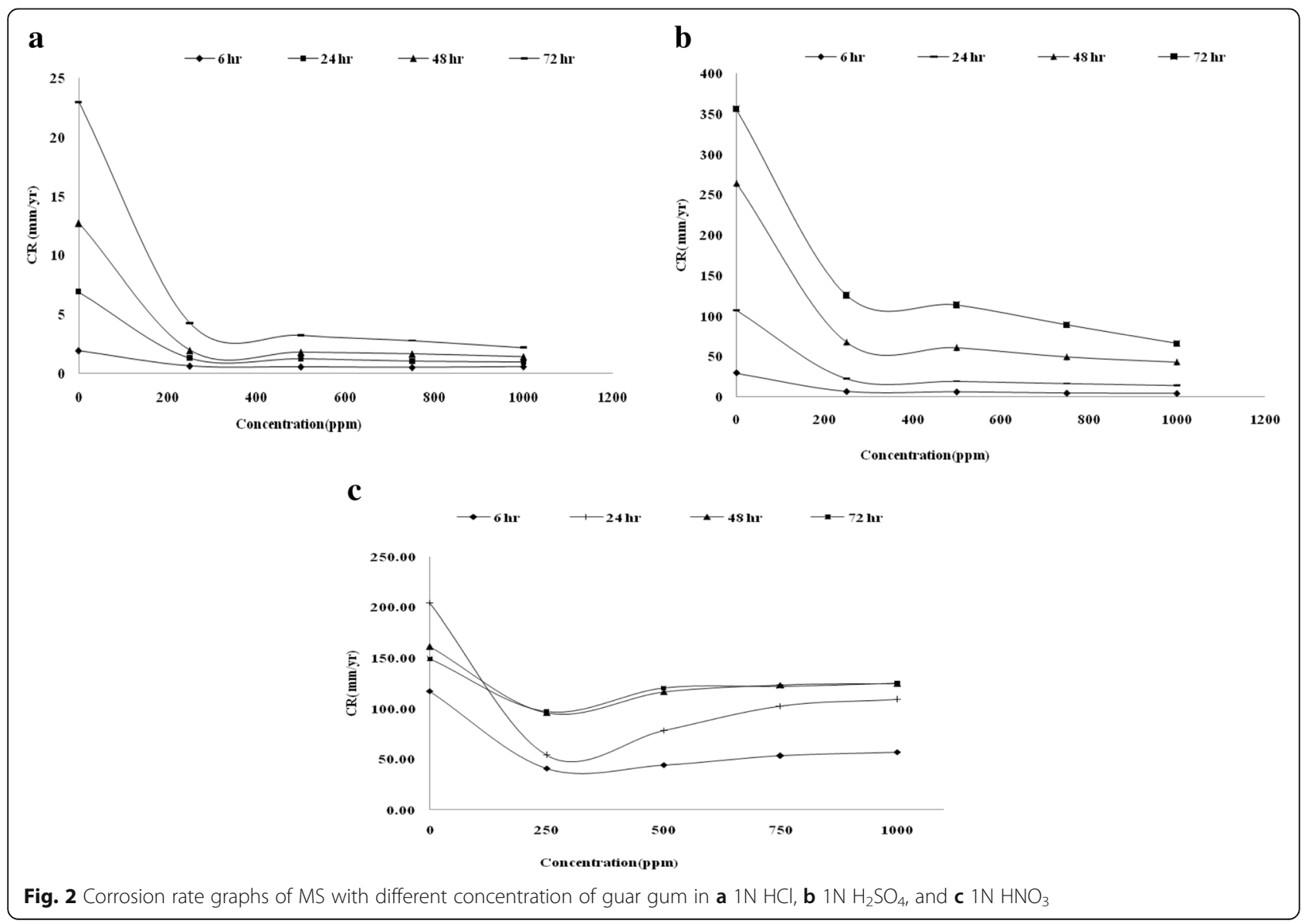




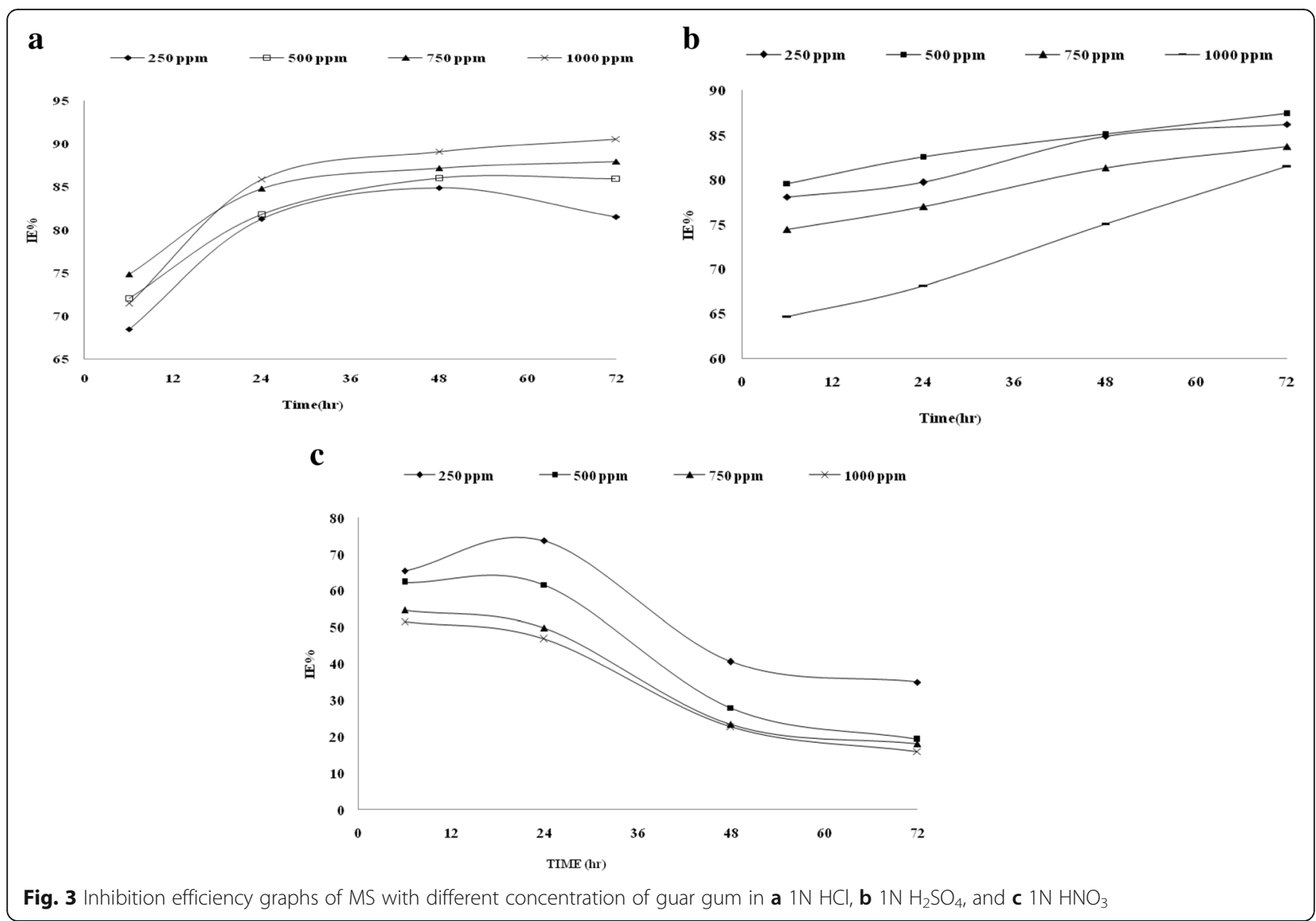

corrosion of mild steel in solutions of $1 \mathrm{~N} \mathrm{HCl,} \mathrm{H}_{2} \mathrm{SO}_{4}$, and $\mathrm{HNO}_{3}$ having different concentrations of guar gum at 304 and $313 \mathrm{~K}$. Obtained straight lines from the plots confirms first order kinetics for the mild steel corrosion inhibition process (Table 3).

\section{Effect of temperature}

Values of activation energy for the corrosion reaction of mild steel in the presence and absence of different concentration of guar gum inhibitor have been calculated using Arrhenius equation

$$
\mathrm{Ea}=2.303 \mathrm{R} \times \log (\mathrm{CR} 1 / \mathrm{CR} 2) /(\mathrm{T} 1-\mathrm{T} 2 / \mathrm{T} 1 \times \mathrm{T} 2)
$$

where $\mathrm{Ea}$ is known as activation energy, the reactant molecules having energy less than the threshold energy must acquire the same in order to react to yield a product. CR1 and CR2 are the corrosion rates of mild steel at the temperatures $\mathrm{T} 1(304 \mathrm{~K})$ and $\mathrm{T} 2(313 \mathrm{~K})$, respectively. Ea, which ranged from 0.9 to $21.69 \mathrm{~kJ} \mathrm{~mol}^{-1}$ in $\mathrm{HCl}$ medium, 1.4 to $32.02 \mathrm{~kJ} \mathrm{~mol}^{-1}$ in $\mathrm{H}_{2} \mathrm{SO}_{4}$ medium, and 0.79 to $10.12 \mathrm{~kJ} \mathrm{~mol}^{-1}$ in $\mathrm{HNO}_{3}$ medium with different concentration of inhibitor (Table 4), which are lower than $40.0 \mathrm{~kJ} \mathrm{~mol}^{-1}$ signifying that the inhibitor is physically adsorbed on the metal surface (Ulman 1991). As a result, the adsorption of guar gum on mild steel surface is steady with the mechanism of physical adsorption.

\section{Thermodynamics/adsorption study}

Heat of adsorption is essential value of heat which is required for inhibitor to be got adsorb on metal surface. In this work, the heat of adsorption of guar gum has calculated using the following equation:

$$
\begin{aligned}
\text { Qads }= & 2.303 R[\log (\theta 2 / 1-\theta 2)-\log (\theta 1 / 1-\theta 1)] \\
& \times \mathrm{T} 1 \mathrm{~T} 2 / \mathrm{T} 2-\mathrm{T} 1
\end{aligned}
$$

Where $\theta 1$ and $\theta 2$ are the degrees of surface coverage of the inhibitor at temperatures, T1 (304 K) and T2 (313 K) respectively and $R$ is the gas constant. Calculated values of Qads are also recorded in Table 4. These values are negative signifying that the adsorption of guar gum on mild steel surface is exothermic. The adsorption character of guar gum have also investigated by fitting data calculated for the degree of surface coverage of the inhibitor into various adsorption isotherms including Langmuir, Freundlich, and Temkin adsorption isotherms. The adsorption of organic inhibitor molecules from the aqueous solution can be considered as a quasi- 

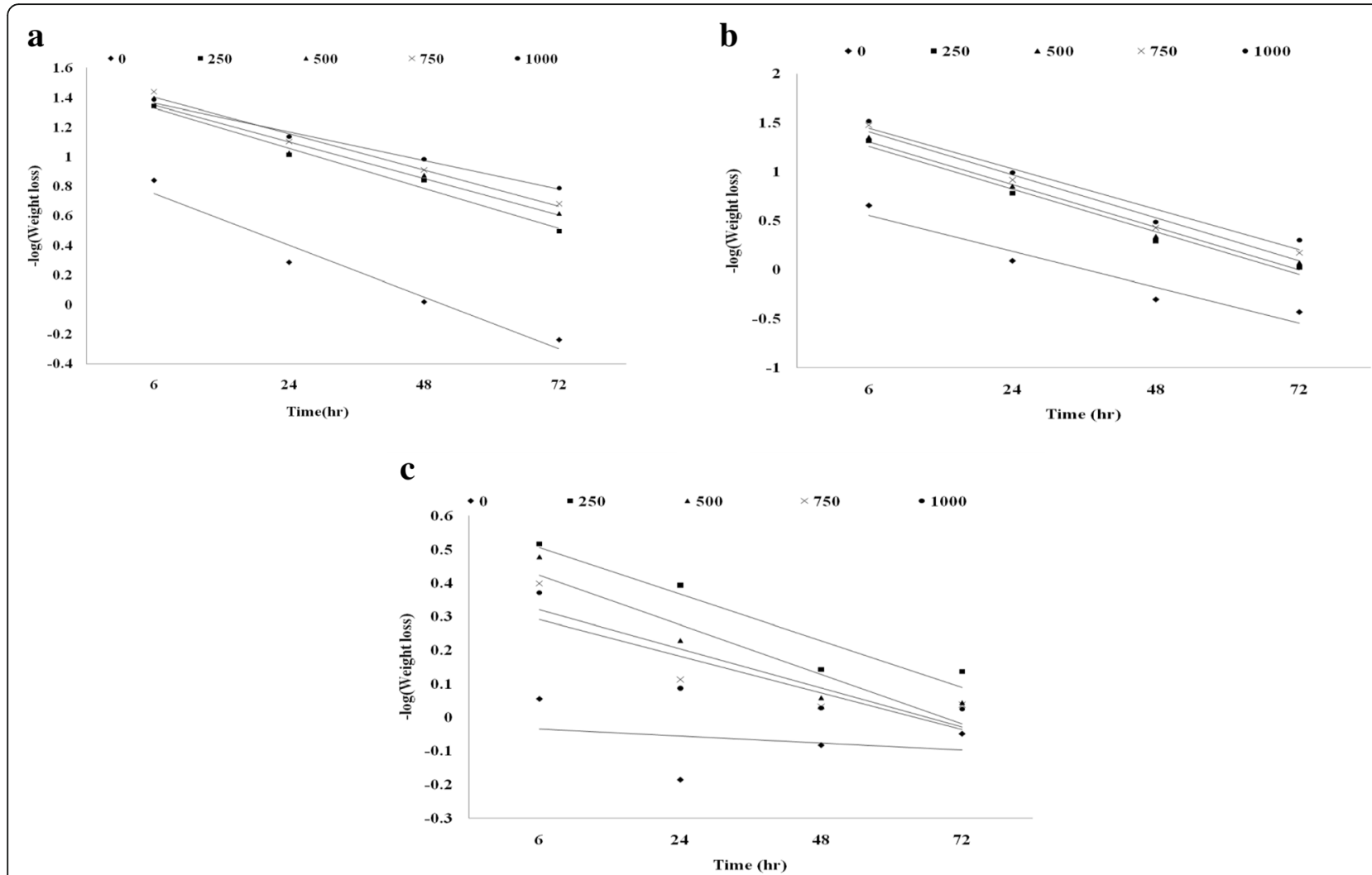

Fig. 4 Variation of -log(weight loss) versus time for the corrosion of mild steel in solutions of a $1 \mathrm{~N} \mathrm{HCl}, \mathbf{b} 1 \mathrm{~N} \mathrm{H}_{2} \mathrm{SO}_{4}$, and $\mathbf{c} 1 \mathrm{~N} \mathrm{HNO}_{3}$ containing various concentrations of guar gum at $304 \mathrm{~K}$ temperature

substitution process between the organic compound in the aqueous phase $\operatorname{Org}(\mathrm{sol})$ and water molecules associated with the metallic surface $\mathrm{H}_{2} \mathrm{O}$ (ads) as represented by the following equilibrium (Eddy and Odoemelam 2008).

$$
\text { Org }(\mathrm{Sol})+\mathrm{xH} 2 \mathrm{O}(\text { ads }) \leftrightarrow \mathrm{Org}(\text { ads })+\mathrm{xH} 2 \mathrm{O}(\mathrm{Sol})
$$

$X$ is the no. of molecules replaced by one organic molecule. In this situation, the adsorption of guar gum was accompanied by desorption of water molecules from the mild steel surface. We calculate the surface coverage $(\theta)$ values by using the formula

$$
\theta=(\mathrm{w} 0-\mathrm{wi}) / \mathrm{w} 0
$$

$\mathrm{w} 0=$ weight loss without inhibitor, wi $=$ weight loss without inhibitor

The mechanism of the interaction between inhibitor and the metal surface can be explained using adsorption isotherms. The degree of surface coverage, for the different systems studied, was computed from the weight loss measurements using Eq. (1) and presented in Table 1. The obtained data best fitted into Langmuir isotherm, which may be formulated as

$$
(C / \theta)=C+1 / \mathrm{Kad}
$$

where, $C$ is the concentration of the inhibitor (guar gum), $\theta$ is the fractional surface coverage, and Kad is the adsorption equilibrium constant. From the intercepts of the straight line $\operatorname{Cinh} / \theta$-axis, $K$ value was calculated and from graph the value came can be justified by theoretical value. It is based on the assumption that the adsorbed molecule decreases the surface area available for the corrosion reactions to occur. Figures 6 and 7 show the plot of $C / \theta$ against $C$ for $[\mathrm{A}] 1 \mathrm{~N} \mathrm{HCl},[\mathrm{B}] 1 \mathrm{~N} \mathrm{H}_{2} \mathrm{SO}_{4}$, and [C] $1 \mathrm{~N}^{\mathrm{HNO}_{3}}$ at 304 and $313 \mathrm{~K}$ temperature. Linear plots were obtained indicating that the experimental results fit into Langmuir isotherm. The calculated values of $B$ (slope) and $K$ (equilibrium constant of adsorption process) obtained from Langmuir are shown in Table 5. $\Delta$ Gads of the inhibitor on mild steel surface was determined by the following formula:

$$
\Delta \mathrm{Gads}=-\mathrm{RT} \ln (\mathrm{K} \mathrm{ad} * 55.5)
$$

$\Delta$ Gads $=$ standard free energy of adsorption, $\mathrm{Kad}=$ eqillibrium constant of adsorption, and $55.5=$ concentration of water in solution $\left(\mathrm{mol} \mathrm{l}^{-1}\right)$. $\Delta$ Gads values around $-20 \mathrm{~kJ} \mathrm{~mol}^{-1}$ or lower are consistent with the electrostatic interaction between charged organic molecules 


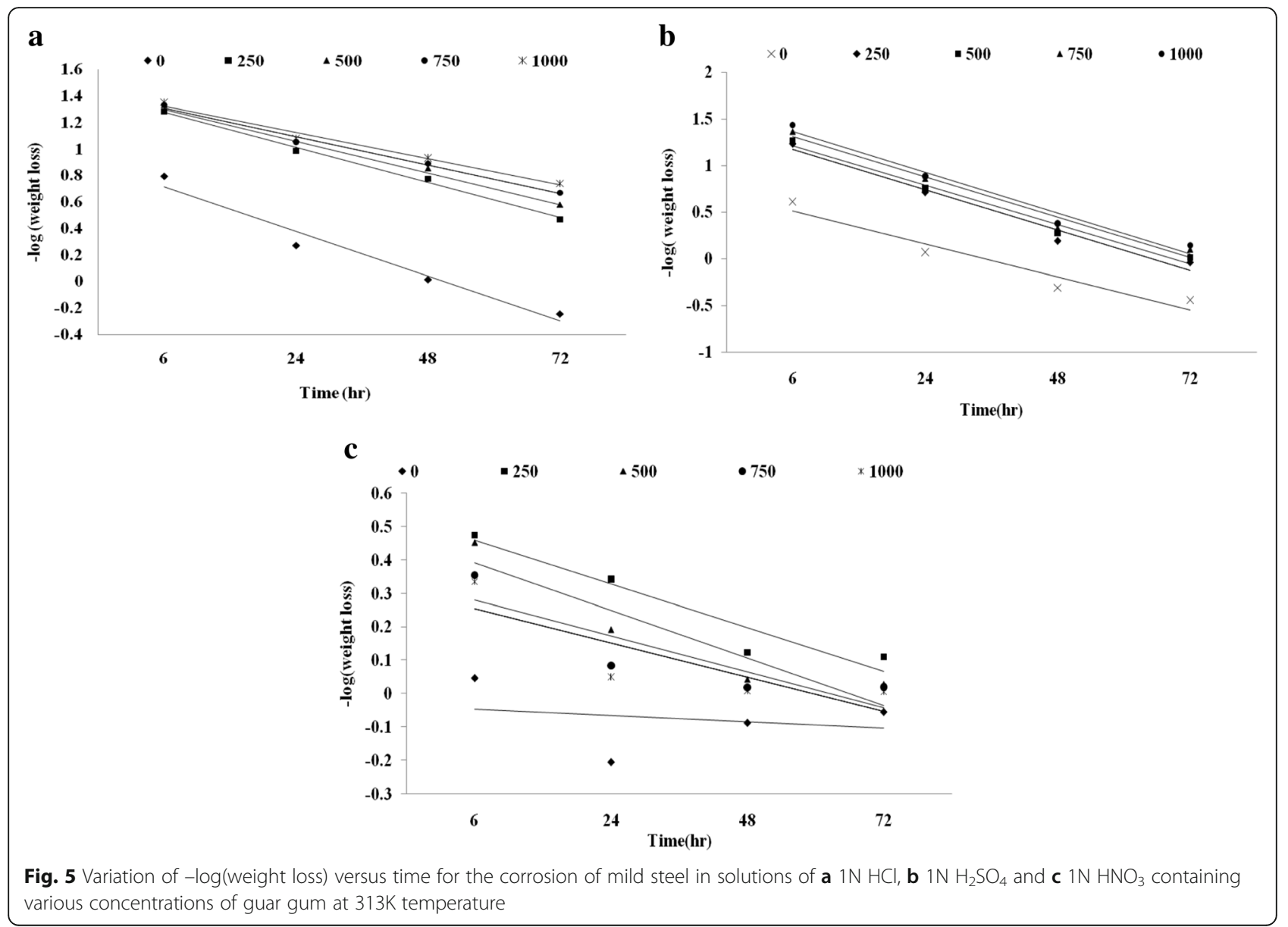

and the charged metal surface (physiorption): those around $-40 \mathrm{~kJ} \mathrm{~mol}^{-1}$ or higher involve charge sharing or transfer from the organic molecules to the metal surface to form a co-ordinate type of bond (chemisorptions). Our reported values for $\Delta \mathrm{Gads} \leq-20 \mathrm{~kJ} \mathrm{~mol}^{-1}$ are less than $-20 \mathrm{~kJ} \mathrm{~mol}^{-1}$, so in our reaction, we reported physiorption. Values of $\Delta \mathrm{Gads}$ and Kad are listed in Table 5.

In case of adsorption by solids from the solutions, mostly the solute is adsorbed on the surface of the solid adsorbent so that the concentration of solute on the

Table 3 Kinetic parameters for the corrosion of mild steel in $1 \mathrm{~N} \mathrm{HCl}, \mathrm{H}_{2} \mathrm{SO}_{4}$, and $\mathrm{HNO}_{3}$ medium containing various concentrations of guar gum at $304 \mathrm{~K}$

\begin{tabular}{|c|c|c|c|c|c|c|c|c|c|c|c|c|}
\hline \multirow[t]{6}{*}{$\overline{1 \mathrm{~N} \mathrm{HCl}}$} & Cont. (ppm) & $B$ & $\mathrm{~K}$ & $R^{2}$ & \multirow[t]{6}{*}{$1 \mathrm{~N} \mathrm{H}_{2} \mathrm{SO}_{4}$} & $B$ & K & $R^{2}$ & \multirow[t]{6}{*}{$1 \mathrm{~N} \mathrm{HNO}_{3}$} & B & K & $R^{2}$ \\
\hline & 0 & -0.35 & 1.1 & 0.96 & & -0.36 & 0.92 & 0.93 & & -0.02 & 0.01 & 0.70 \\
\hline & 250 & -0.27 & 1.6 & 0.99 & & -0.44 & 1.7 & 0.98 & & -0.14 & 0.64 & 0.90 \\
\hline & 500 & -0.25 & 1.6 & 0.97 & & -0.44 & 1.74 & 0.98 & & -0.15 & 0.57 & 0.89 \\
\hline & 750 & -0.25 & 1.65 & 0.99 & & -0.44 & 1.85 & 0.98 & & -0.12 & 0.44 & 0.76 \\
\hline & 1000 & -0.19 & 1.56 & 0.99 & & -0.41 & 1.86 & 0.96 & & -0.11 & 0.4 & 0.74 \\
\hline \multicolumn{13}{|l|}{$313 \mathrm{~K}$} \\
\hline \multirow[t]{5}{*}{$1 \mathrm{~N} \mathrm{HCl}$} & 0 & -0.34 & 1.05 & 0.96 & \multirow[t]{5}{*}{$1 \mathrm{~N} \mathrm{H}_{2} \mathrm{SO}_{4}$} & -0.35 & 0.87 & 0.94 & \multirow[t]{5}{*}{$1 \mathrm{~N} \mathrm{HNO}_{3}$} & -0.02 & 0.03 & 0.93 \\
\hline & 250 & -0.26 & 1.54 & 0.99 & & -0.43 & 1.61 & 0.97 & & -0.13 & 0.59 & 0.92 \\
\hline & 500 & -0.22 & 1.52 & 0.98 & & -0.42 & 1.64 & 0.98 & & -0.14 & 0.53 & 0.87 \\
\hline & 750 & -0.24 & 1.54 & 0.98 & & -0.43 & 1.75 & 0.94 & & -0.11 & 0.39 & 0.74 \\
\hline & 1000 & -0.2 & 1.52 & 0.99 & & -0.44 & 1.8 & 0.97 & & -0.1 & 0.36 & 0.71 \\
\hline
\end{tabular}


Table 4 Calculated values of apparent activation energy (Ea) and Heat of adsorption (Q) of guar gum on mild steel in $1 \mathrm{~N} \mathrm{HCl}$, $\mathrm{H}_{2} \mathrm{SO}_{4}$ and $\mathrm{HNO}_{3}$ medium

\begin{tabular}{|c|c|c|c|c|c|c|c|c|c|}
\hline \multirow{2}{*}{$\begin{array}{l}\text { Guar gum } \\
\text { concentration } \\
\text { (ppm) }\end{array}$} & \multirow[t]{2}{*}{ Medium } & \multicolumn{4}{|l|}{ Ea $\left(\mathrm{kJ} \mathrm{mol}{ }^{-1}\right)$} & \multicolumn{4}{|c|}{ Qads $\left(\mathrm{kJ} \mathrm{mol}{ }^{-1}\right)$} \\
\hline & & $6 \mathrm{~h}$ & $24 \mathrm{~h}$ & $48 \mathrm{~h}$ & $72 \mathrm{~h}$ & $6 \mathrm{~h}$ & $24 \mathrm{~h}$ & $48 \mathrm{~h}$ & $72 \mathrm{~h}$ \\
\hline 0 & $1 \mathrm{~N} \mathrm{HCl}$ & 9.27250789 & 2.90507331 & 0.9139064 & 1.36911847 & - & - & - & - \\
\hline 250 & & 11.848584 & 5.58216111 & 12.9549107 & 5.19003643 & -3.75007014 & -4.43960607 & -5.22802254 & -4.21395543 \\
\hline 500 & & 12.8788011 & 6.29318179 & 4.32023085 & 7.31956056 & -7.53960158 & -7.82935384 & -9.85802469 & -10.7977925 \\
\hline 750 & & 21.6914682 & 10.3215288 & 4.47333994 & 2.8048226 & -10.0039872 & -10.915953 & -12.1317652 & -14.818384 \\
\hline 1000 & & 6.56409778 & 10.947072 & 10.1705685 & 9.94213687 & -7.6629907 & -10.8511463 & -13.051503 & -17.5339037 \\
\hline 0 & $1 \mathrm{~N} \mathrm{H}_{2} \mathrm{SO}_{4}$ & 8.8401921 & 3.52688474 & 1.41960241 & 1.50081477 & - & - & - & - \\
\hline 250 & & 16.5049372 & 13.2543419 & 20.1025875 & 12.0519032 & -6.17484905 & -6.84773222 & -10.0018618 & -11.1406732 \\
\hline 500 & & 17.1777765 & 19.3215751 & 12.9564535 & 10.8190683 & -6.80674183 & -8.4132127 & -10.1549509 & -12.5647234 \\
\hline 750 & & 22.8243155 & 12.1771338 & 20.733607 & 15.6261701 & -5.22040277 & -5.85683963 & -7.75697335 & -9.24900021 \\
\hline 1000 & & 17.421718 & 21.6080439 & 22.5823843 & 32.02365 & -3.34592498 & -3.79544558 & -5.29988713 & -7.99889198 \\
\hline 0 & $1 \mathrm{~N} \mathrm{HNO}_{3}$ & 1.77304033 & 3.55516654 & 0.79157225 & 1.08495861 & - & - & - & - \\
\hline 250 & & 8.30698807 & 10.1277979 & 3.89375612 & 5.43939158 & -3.36869057 & -2.96013092 & -2.41242305 & -2.20720793 \\
\hline 500 & & 5.32116501 & 7.53342455 & 3.0589423 & 3.12703952 & -4.84997347 & -2.89713752 & -2.05965033 & -1.9731825 \\
\hline 750 & & 8.84421126 & 5.7499852 & 2.72675645 & 3.5886785 & -1.79641201 & -1.70305171 & -1.74738879 & -1.82442233 \\
\hline 1000 & & 7.05913228 & 7.25875797 & 4.03907321 & 3.7658194 & -1.76463022 & -1.85561621 & -1.92276054 & -2.03325308 \\
\hline
\end{tabular}

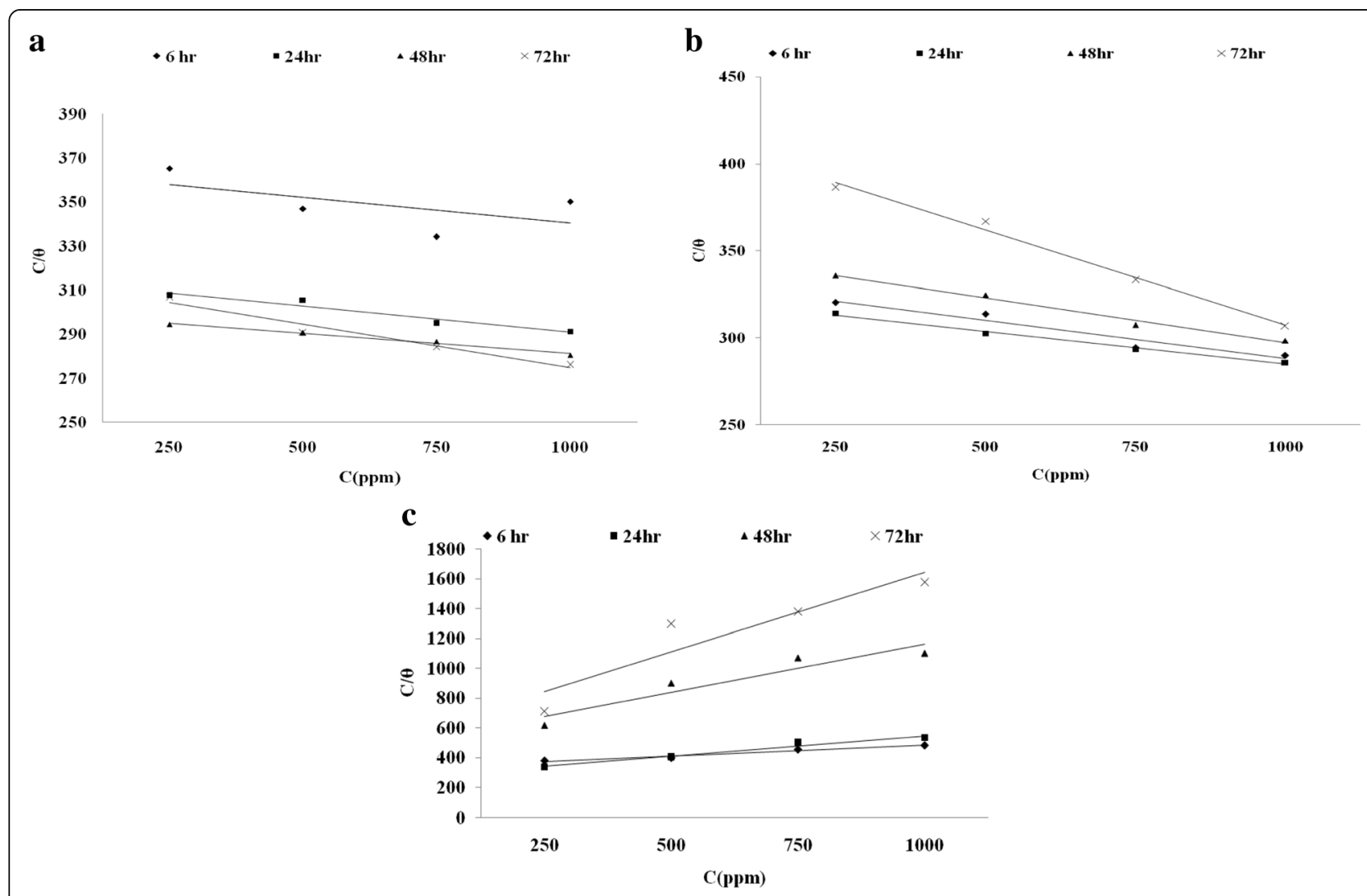

Fig. 6 Adsorption isotherms for the guar gum on mild steel in different acid medium at $304 \mathrm{~K}$ temperature. Langmuir isotherm in a $1 \mathrm{~N} \mathrm{HCl}$, $\mathbf{b} 1 \mathrm{~N}$ $\mathrm{H}_{2} \mathrm{SO}_{4}$, and c $1 \mathrm{~N} \mathrm{HNO}_{3}$ 


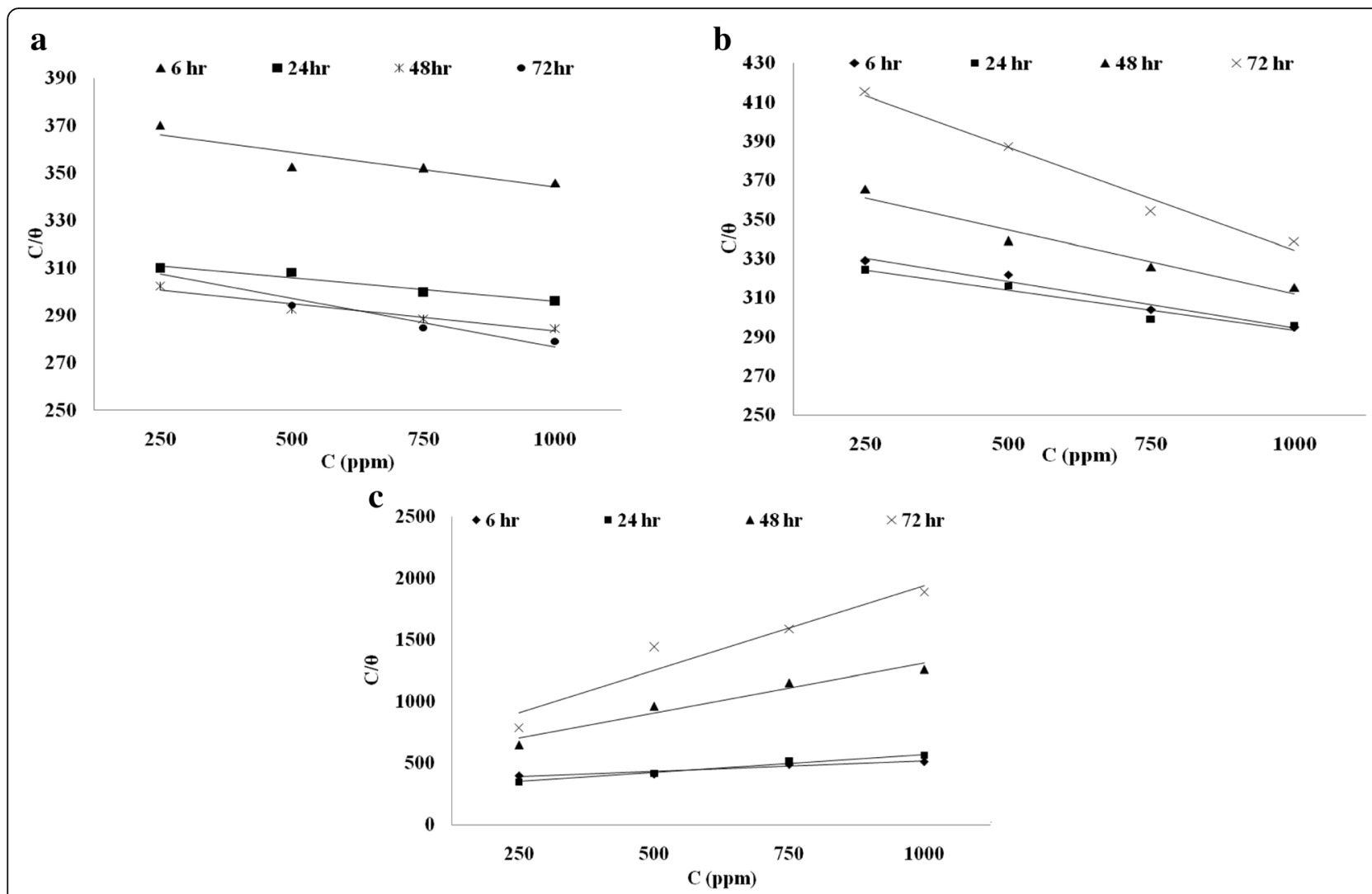

Fig. 7 Adsorption isotherms for the guar gum on mild steel in different acid medium at $313 \mathrm{~K}$ temperature. Langmuir isotherm in a $1 \mathrm{~N} \mathrm{HCl,} \mathbf{b} 1 \mathrm{~N}$ $\mathrm{H}_{2} \mathrm{SO}_{4}$, and c $1 \mathrm{~N} \mathrm{HNO}_{3}$

surface of the adsorbent is greater than in the bulk. This is known as positive adsorption. In some cases, the solvent from the solution may be absorbed by the adsorbent so that the concentration of the solution increases than the initial concentration. This is called negative adsorption. Hence, if the concentration of the adsorbate is less on the surface of the adsorbent than in the bulk, it is known as negative adsorption.

We observed the low and negative values of $\Delta G$ during this study, which show probability of physiosorption. Electrostatic interaction between the charged metal and charged molecules signifies physical adsorption. Applicability of

Table 5 Parameters for the adsorption of guar gum on mild steel surface at 304 and $313 \mathrm{~K}$ temperature

\begin{tabular}{|c|c|c|c|c|c|c|c|c|c|c|c|}
\hline \multirow[b]{2}{*}{ Applied isotherm } & \multirow[b]{2}{*}{ Medium } & \multicolumn{6}{|l|}{$304 \mathrm{~K}$} & \multicolumn{4}{|l|}{$313 \mathrm{~K}$} \\
\hline & & $\begin{array}{l}\text { Cont. } \\
\text { (ppm) }\end{array}$ & $\begin{array}{l}\text { Time } \\
\text { (hours) }\end{array}$ & B & Kads $\left(\mathrm{ppm}^{-1}\right)$ & $R^{2}$ & $\Delta$ Gads $\left(\mathrm{k} J \mathrm{~mol}^{-1}\right)$ & B & Kads $\left(\mathrm{ppm}^{-1}\right)$ & $R^{2}$ & $\Delta$ Gads $\left(\mathrm{kJ} \mathrm{mol}^{-1}\right)$ \\
\hline \multirow{4}{*}{$\begin{array}{l}\text { Langmuir adsorption } \\
\text { isotherm }\end{array}$} & \multirow[t]{4}{*}{$1 \mathrm{~N} \mathrm{HCl}$} & 250 & 6 & -5.81 & 363.6 & 0.95 & -25.05 & -7.365 & 373.6 & 0.82 & -25.12 \\
\hline & & 500 & 24 & -5.97 & 314.7 & 0.93 & -24.68 & -5.026 & 315.9 & 0.94 & -24.69 \\
\hline & & 750 & 48 & -4.56 & 299.48 & 0.92 & -24.56 & -5.782 & 306.3 & 0.95 & -24.61 \\
\hline & & 1000 & 72 & -9.87 & 314.16 & 0.96 & -24.68 & -10.19 & 317.4 & 0.96 & -24.70 \\
\hline \multirow{4}{*}{$\begin{array}{l}\text { Langmuir adsorption } \\
\text { isotherm }\end{array}$} & \multirow[t]{4}{*}{$1 \mathrm{~N} \mathrm{H}_{2} \mathrm{SO}_{4}$} & 250 & 6 & -11.03 & 332.24 & 0.94 & -24.82 & -11.98 & 342.3 & 0.97 & -24.90 \\
\hline & & 500 & 24 & -9.39 & 322.65 & 0.99 & -24.75 & -26.32 & 439.6 & 0.98 & -25.53 \\
\hline & & 750 & 48 & -12.91 & 348.93 & 0.99 & -24.94 & -16.41 & 377.4 & 0.96 & -25.14 \\
\hline & & 1000 & 72 & -27.26 & 416.58 & 0.99 & -25.39 & -10.61 & 334 & 0.95 & -24.83 \\
\hline \multirow{4}{*}{$\begin{array}{l}\text { Langmuir adsorption } \\
\text { isotherm }\end{array}$} & \multirow[t]{4}{*}{$1 \mathrm{NHNO}_{3}$} & 250 & 6 & 36.25 & 340.67 & 0.97 & -24.88 & 42.72 & 347.1 & 0.93 & -24.93 \\
\hline & & 500 & 24 & 68.21 & 274.95 & 0.99 & -24.34 & 73.67 & 276.8 & 0.98 & -24.36 \\
\hline & & 750 & 48 & 162.4 & 515.44 & 0.89 & -25.93 & 202.5 & 501.5 & 0.95 & -25.86 \\
\hline & & 1000 & 72 & 266.5 & 577.21 & 0.86 & -26.22 & 343.5 & 568.1 & 0.92 & -26.18 \\
\hline
\end{tabular}


Langmuir adsorption isotherm of adsorption of guar gum confirms formation of multi-molecular layer of adsorption where there is no interaction between adsorbate and adsorbent.

\section{Adsorption mechanism}

The process of mild steel dissolution in acidic medium i.e., $\left(1 \mathrm{~N} \mathrm{HCl}, 1 \mathrm{~N} \mathrm{H}_{2} \mathrm{SO}_{4}\right.$, and $1 \mathrm{~N} \mathrm{HNO}_{3}$ ) depends on concentration of anions in the solution as observed

$$
\begin{aligned}
& \mathrm{Fe}+\mathrm{Cl} \leftrightarrow\left(\mathrm{FeCl}^{-}\right)_{\mathrm{ads}}+\mathrm{e}^{-} \\
& \left(\mathrm{FeCl}^{-}\right)_{\mathrm{ads}} \leftrightarrow(\mathrm{FeCl})_{\mathrm{ads}}+\mathrm{e}^{-} \\
& (\mathrm{FeCl})_{\mathrm{ads}} \leftrightarrow \mathrm{FeCl}^{+}+\mathrm{e}- \\
& \mathrm{FeCl}^{+} \leftrightarrow \mathrm{Fe}^{+}+\mathrm{Cl}^{-}
\end{aligned}
$$

when we add guar gum (GG) as inhibitor to acid solution, different additional steps are involved depending on the nature of the electrolyte in mechanism of anodic dissolution

$$
\begin{aligned}
& \left(\mathrm{FeCl}^{-}\right)_{\mathrm{ads}}+\mathrm{H}^{+} \mathrm{GG} \leftrightarrow\left(\mathrm{FeCl}^{-} \mathrm{H}^{+} \mathrm{GG}\right)_{\mathrm{ads}} \\
& \left(\mathrm{FeCl}^{-} \mathrm{H}^{+} \mathrm{GG}\right)_{\mathrm{ads}} \leftrightarrow\left(\mathrm{FeH}^{+} \mathrm{GG}\right)_{\mathrm{ads}}+\mathrm{Cl}^{-}
\end{aligned}
$$

In acidic medium reduction, mechanism is not affected by the presence of the inhibitor because hydrogen evolution is activated controlled step. Due to this, there is retardation in the rate of cathodic reaction by the inhibitor and the possible pathways of the cathodic reaction are the following

$$
\begin{aligned}
& \mathrm{Fe}^{+} \mathrm{H}^{+}+\mathrm{e}^{-} \leftrightarrow(\mathrm{FeH})_{\mathrm{ads}} \\
& \mathrm{Fe}+\left(\mathrm{H}^{+} \mathrm{GG}\right)+\mathrm{e}^{-} \leftrightarrow(\mathrm{FeH} \mathrm{GG})_{\mathrm{ads}} \\
& (\mathrm{FeH})_{\mathrm{ads}}+(\mathrm{FeH} \mathrm{GG})_{\mathrm{ads}} \leftrightarrow \mathrm{Fe}+\mathrm{H}_{2}
\end{aligned}
$$

By all this reaction mechanism, we get to know that there is competition between $\mathrm{H}^{+}$and $\mathrm{H}^{+} \mathrm{GG}$ (protonated inhibitor) for the same active site to get adsorbed on the surface.

Abovementioned mechanism is applicable to $\mathrm{HCl}$, $\mathrm{H}_{2} \mathrm{SO}_{4}$, and $\mathrm{HNO}_{3}$. In Fig. 8, we are showcasing comparative inhibition capacity of guar gum inhibitor for mild steel corrosion in all acidic mediums. Where we found that in $1 \mathrm{~N} \mathrm{HCl}$ inhibitor efficacy increases with increasing concentration but in $1 \mathrm{~N} \mathrm{H}_{2} \mathrm{SO}_{4}$ and $1 \mathrm{~N}$ $\mathrm{HNO}_{3}$, it increases up to maximum limit and after that, it falls. It is noted that, the obtained inhibition results are comparatively better in $\mathrm{HCl}$ and $\mathrm{H}_{2} \mathrm{SO}_{4}$ in comparision of $\mathrm{HNO}_{3}$.

Guar gum has been found to be a good corrosion inhibitor. The corrosion control potential of this gum can
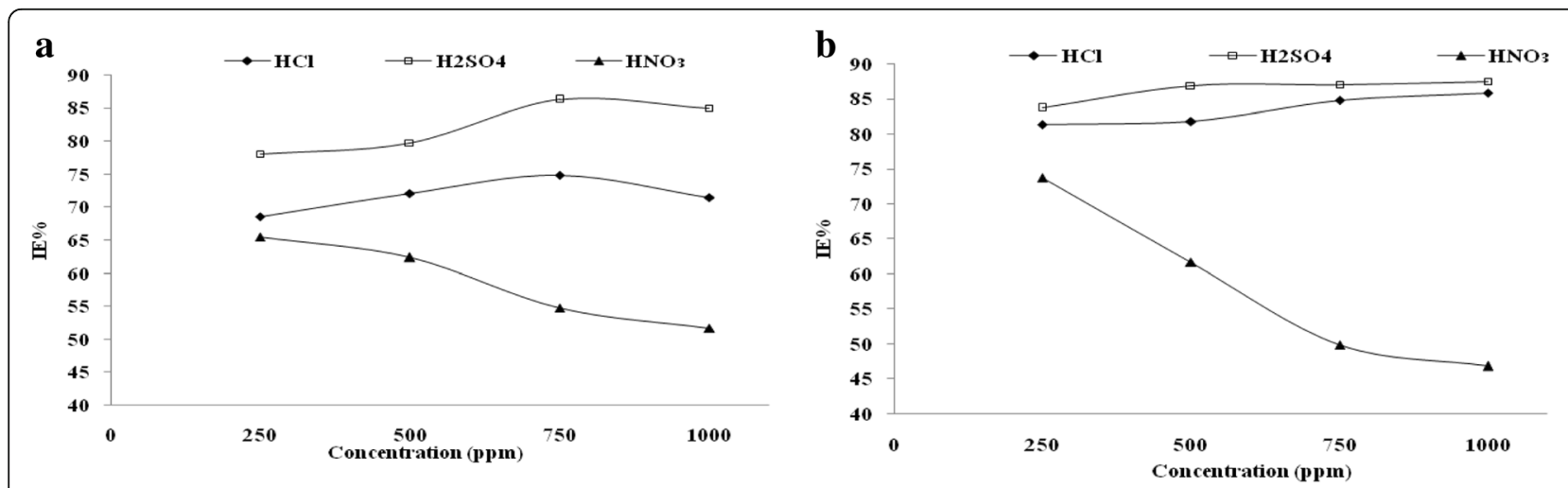

c

d
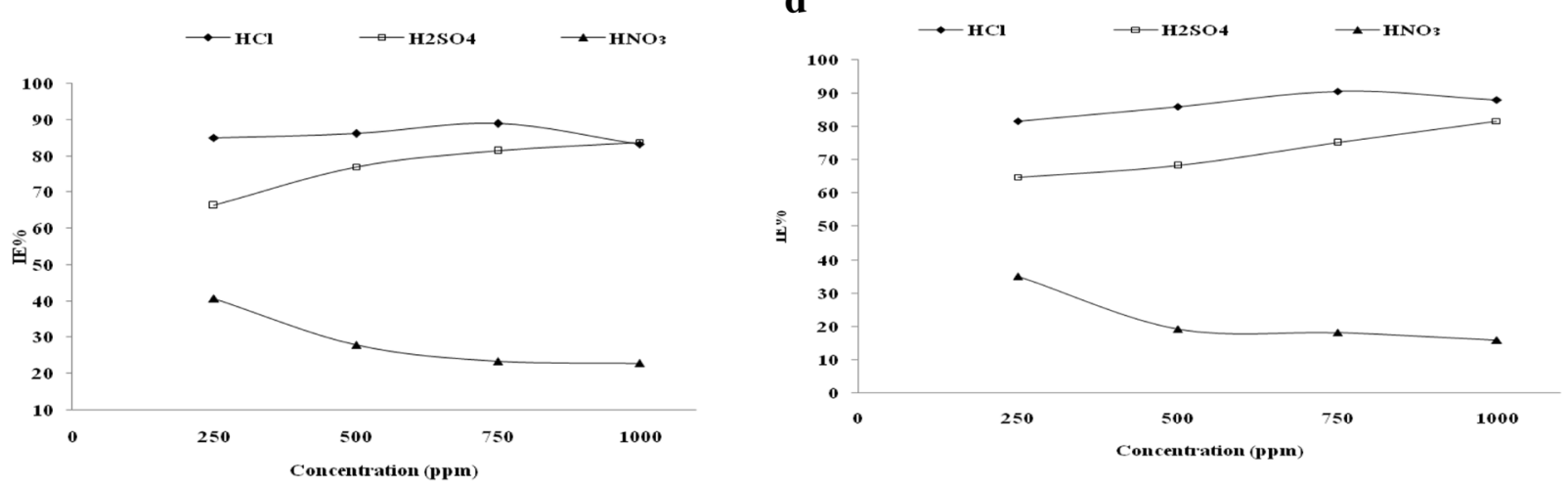

Fig. 8 Comparative analysis graphs of mild steel corrosion $1 \mathrm{~N} \mathrm{HCl} \mathrm{H}_{2} \mathrm{SO}_{4}$, and $\mathrm{HNO}_{3}$ at a 6 h. b $24 \mathrm{~h}$. c 48 h. d $72 \mathrm{~h}$ 


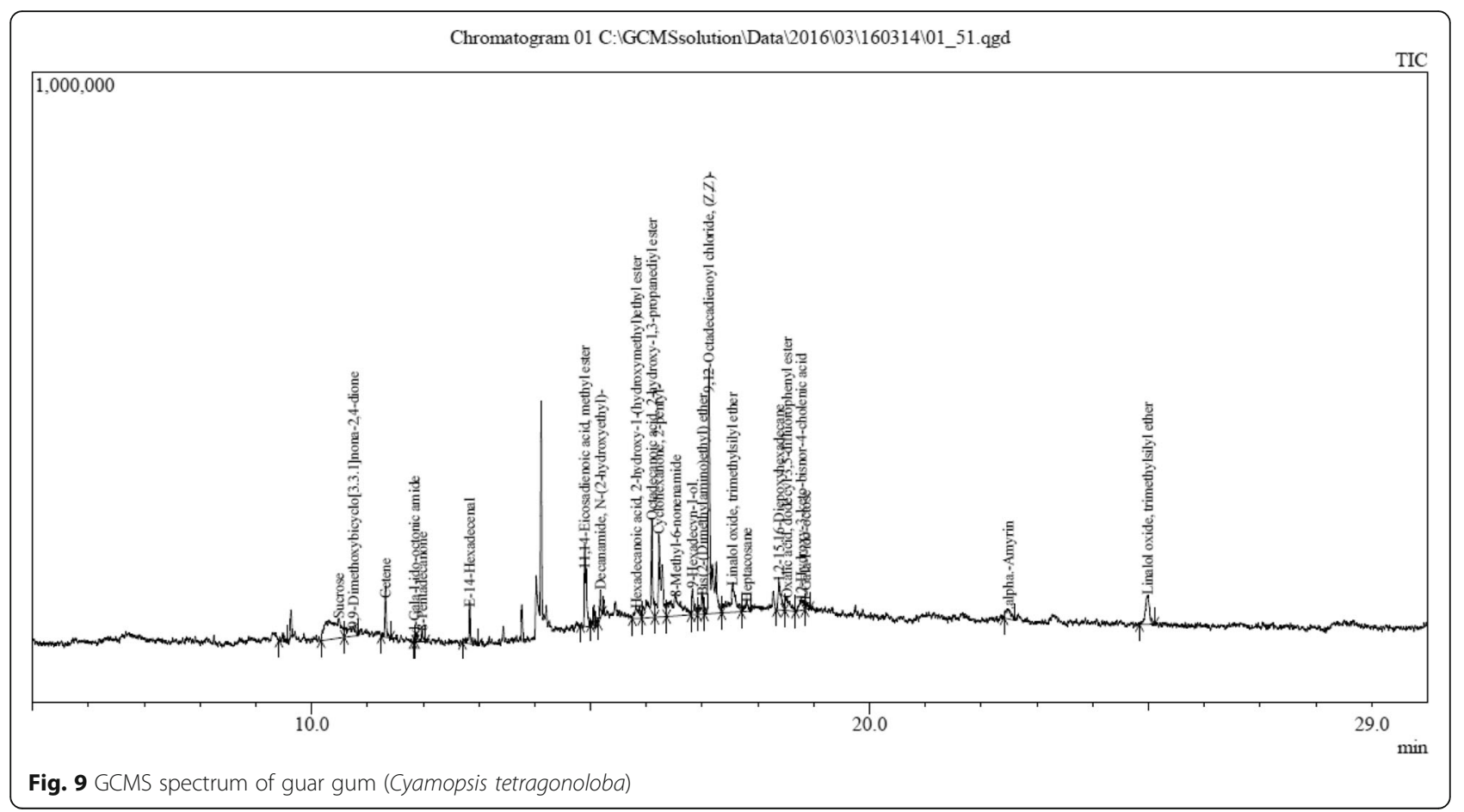

Table 6 GC-MS spectrum details of guar gum

\begin{tabular}{|c|c|c|c|c|c|c|}
\hline Peak & R. time & F.Time & Area & Area \% & $\mathrm{A} / \mathrm{H}$ & Name \\
\hline 1. & 10.492 & 10.590 & 555735 & 9.86 & 18.66 & Sucrose \\
\hline 2. & 10.755 & 10.830 & 157038 & 2.79 & 12.29 & 9,9-Dimethoxybicyclo[3.3.1]nona-2,4-dione \\
\hline 3. & 11.328 & 11.415 & 127449 & 2.26 & 1.91 & Cetene \\
\hline 4. & 11.850 & 11.865 & 17081 & 0.30 & 1.53 & d-Gala--ido-octonic amide \\
\hline 5. & 11.985 & 12.045 & 66373 & 1.18 & 3.54 & 8-Pentadecanone \\
\hline 6. & 12.840 & 12.990 & 144423 & 2.56 & 2.42 & E-14-Hexadecenal \\
\hline 7. & 14.904 & 15.090 & 386001 & 6.85 & 4.08 & 11,14-Eicosadienoic acid, methyl ester \\
\hline 8. & 15.182 & 15.210 & 65176 & 1.16 & 1.79 & Decanamide, N-(2-hydroxyethyl)- \\
\hline 9. & 15.825 & 15.915 & 106873 & 1.90 & 6.04 & Hexadecanoic acid, 2-hydroxy-1-(hydroxymethyl \\
\hline 10. & 16.101 & 16.155 & 451646 & 8.01 & 3.88 & Octadecanoic acid, 2-hydroxy-1,3-propanediyl \\
\hline 11. & 16.230 & 16.365 & 541503 & 9.61 & 4.94 & Cyclohexanone, 2-pentyl- \\
\hline 12. & 16.530 & 16.800 & 401248 & 7.12 & 12.34 & 8-Methyl-6-nonenamide \\
\hline 13. & 16.830 & 16.920 & 122353 & 2.17 & 3.10 & 9-Hexadecyn-1-ol \\
\hline 14. & 17.010 & 17.040 & 105093 & 1.86 & 3.35 & Bis(2-(Dimethylamino)ethyl) ether \\
\hline 15. & 17.126 & 17.355 & 1192462 & 21.16 & 3.49 & 9,12-Octadecadienoyl chloride, (Z,Z)- \\
\hline 16. & 17.550 & 17.700 & 335697 & 5.96 & 7.72 & Linalol oxide, trimethylsilyl ether \\
\hline 17. & 17.803 & 17.880 & 67532 & 1.20 & 4.16 & Heptacosane \\
\hline 18. & 18.379 & 18.480 & 179897 & 3.19 & 3.74 & 1,2-15,16-Diepoxyhexadecane \\
\hline 19. & 18.525 & 18.675 & 112550 & 2.00 & 6.01 & Oxalic acid, dodecyl 3,5-difluorophenyl ester \\
\hline 20. & 18.778 & 18.840 & 96726 & 1.72 & 6.02 & 12-Hydroxy-3-keto-bisnor-4-cholenic acid \\
\hline 21. & 18.855 & 18.930 & 36498 & 0.65 & 2.66 & -Gala-l-ido-octose \\
\hline 22. & 22.493 & 22.605 & 101434 & 1.80 & 6.76 & .alpha.-Amyrin \\
\hline 23. & 24.984 & 25.110 & 229530 & 4.07 & 5.14 & Linalol oxide, trimethylsilyl ether \\
\hline
\end{tabular}



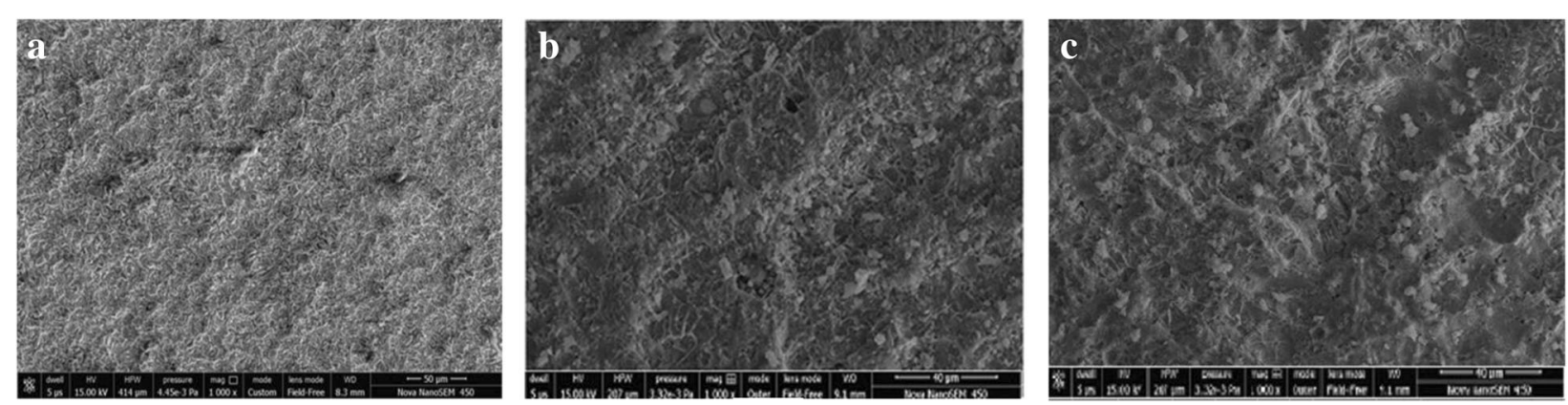

Fig. 10 SEM images of mild steel with $\mathrm{HCl}$ on 40- $\mu \mathrm{m}$ a Polished MS, b MS without inhibitor, and c MS with inhibitor (1000 ppm, $72 \mathrm{~h}$ )

be defined in expressions of interaction between the metal and the gum. Most efficient corrosion inhibitors are long carbon chain or aromatic compounds that have heteroatoms ( $, S, P$, and $\mathrm{O})$ in their system. The present of $\pi$-electron rich functional groups have also been found to enhance inhibition efficiency of a corrosion inhibitor. Figure 9 and Table 6 show the GCMS chromatograph of guar gum and the corrosion product, respectively.

\section{SEM analysis}

The surface morphology of treated mild steel examined by scanning electron microscope is shown in Fig. 10 for samples treated with $1 \mathrm{~N}$ hydrochloric acid solution, Fig. 11 for samples treated with $1 \mathrm{~N}$ sulfuric acid solution, and Fig. 12 for sample treated with $\mathrm{HNO}_{3}$ solution. Each figure shows scanning electron micrographs of the tested surfaces with and without inhibitor. Besides all, three figures show the surface morphology of plain mild steel. Scanning electron micrograph of plain mild steel shows analogous grooves with moderately light areas, which were identified as clean surface. Figure 10 shows the surface morphology of plain mild steel and mild steel exposed to $1 \mathrm{~N}$ hydrochloric acid without inhibitor or with inhibitor on best potent efficiency $(1000 \mathrm{ppm}$, $72 \mathrm{~h}$ ), Fig. 11 shows the surface morphology of plain mild steel and mild steel exposed to $1 \mathrm{~N} \mathrm{H} 2 \mathrm{SO} 4$ in the without inhibitor or with inhibitor on best potent efficiency (1000 ppm, $24 \mathrm{~h}$ ), and in Fig. 12, we obtained the surface morphology of plain mild steel and mild steel exposed to $1 \mathrm{~N} \mathrm{HNO}_{3}$ in the without inhibitor or with inhibitor on best potent efficiency (250 ppm, $24 \mathrm{~h}$ ). Uniform severe corrosion can be observed in the absence of inhibitor for the three acids (Figs. 10, 11, and 12) showing fanatic shapeless corrosion products.

Despite the fact that the obtained SEM results for mild steel in existence of inhibitor suggests that the metal surface is moderately envolved with inhibitor, it is noticeable that the surface is more covered with inhibitor in company of hydrochloric acid (Fig. 10) as compared with the other two acids (Figs. 11 and 12).

\section{Conclusions}

- Guar gum inhibitor adsorption follows the Langmuir adsorption isotherm with all three acids at 304 and $313 \mathrm{~K}$ temperature.

- In $\mathrm{HCl}$ solution, inhibition efficiency gradually increases with increasing concentration of inhibitor up to $1000 \mathrm{ppm}$ at $72 \mathrm{~h}$.

- In $\mathrm{H}_{2} \mathrm{SO}_{4}$ solution, inhibition efficiency rapidly increases with increasing concentration up to (1000 ppm, $24 \mathrm{~h})$. After that there is fall in inhibition due to limited adsorption site or overlapping of inhibitor molecules. But fall of
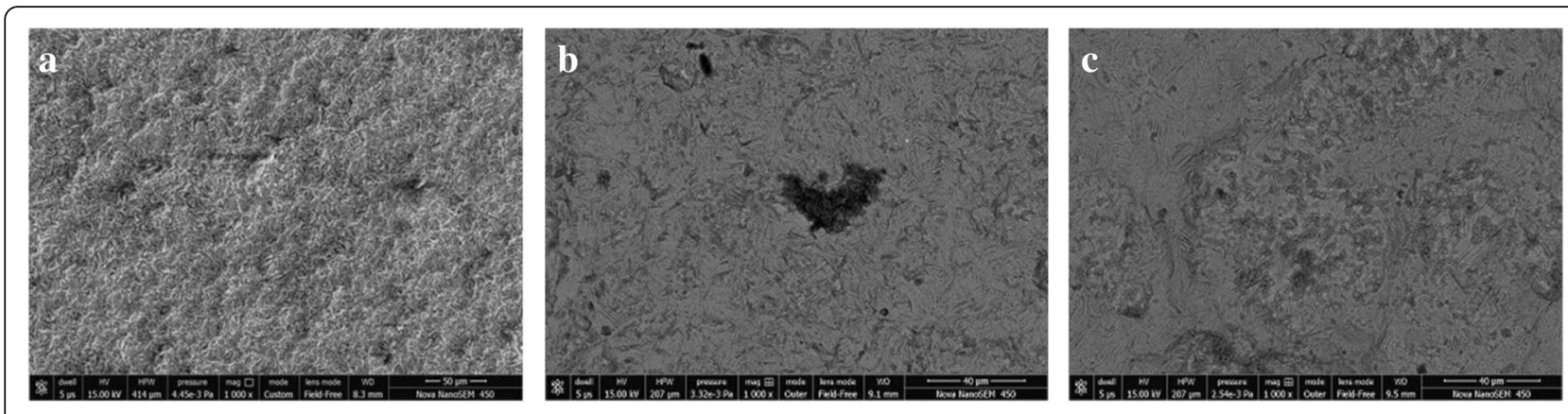

Fig. 11 SEM images of mild steel with $\mathrm{H}_{2} \mathrm{SO}_{4}$ on 40- $\mu \mathrm{m}$ a Polished MS, b MS without inhibitor, and c MS with inhibitor (1000 ppm, 24 h) 

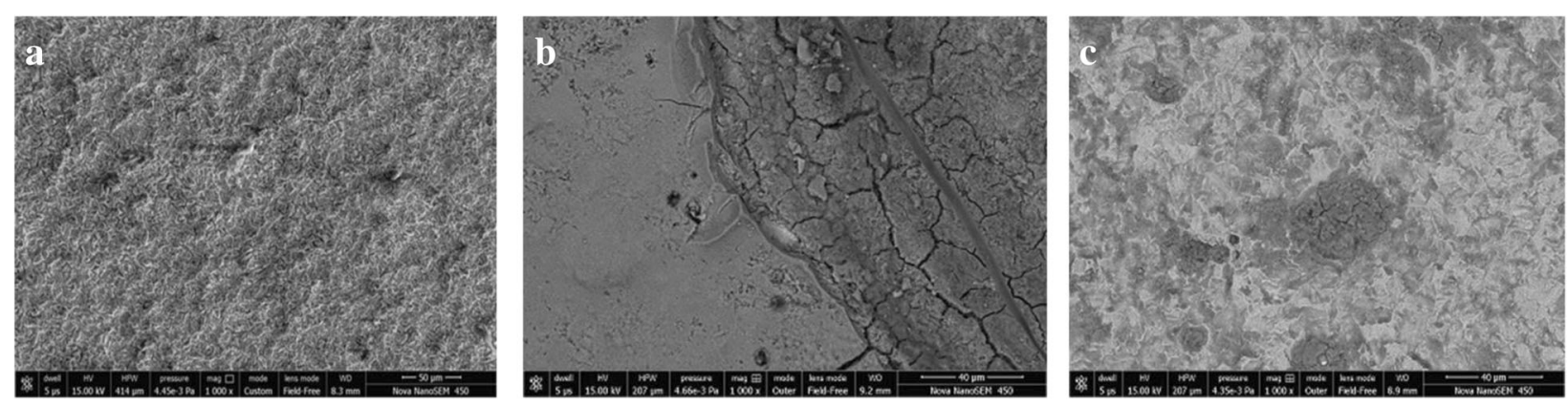

Fig. 12 SEM images of mild steel with $\mathrm{HNO}_{3}$ on 40- $\mu \mathrm{m}$ a Polished MS, b MS without inhibitor, and c MS with inhibitor (250 ppm, 24 h)

inhibition maintains the increasing mode of inhibition with low inhibition values.

- In $\mathrm{HNO}_{3}$ solution, inhibition efficiency reported high on initial level (6 h, $500 \mathrm{ppm})$ after that collapse in inhibition due to hyper oxidizing nature of $\mathrm{HNO}_{3}$ acid.

- According to obtained result, guar gum adsorption on metal surface was spontaneous, exothermic, and supported the mechanism of physical adsorption.

- Comparatively guar gum work as effective inhibitor in $\mathrm{HCl}$ solution as compared to $\mathrm{H}_{2} \mathrm{SO}_{4}$ and $\mathrm{HNO}_{3}$.

\section{Acknowledgements}

Author (AP) thankfully acknowledge the scholarship given by the president of JECRC University for her PhD work.

\section{Authors' contributions}

All experimental works were done by AP. SKS contributed in the results and discussions. IBO contributed in the isothermal studies. All contributing authors have approved the manuscript for submission.

\section{Competing interests}

This work is originally done by us and not submitted elsewhere for publication. We also confirm that the authors declare that they have no competing interests.

\section{Author details}

${ }^{1}$ Green Chemistry \& Sustainability Research Group, Department of Chemistry, JECRC University, Jaipur 303905, India. ${ }^{2}$ Centre of Research Excellence in Corrosion, King Fahd University of Petroleum and Minerals, Dhahran 31261, Kingdom of Saudi Arabia.

Received: 30 June 2016 Accepted: 24 November 2016 Published online: 01 December 2016

\section{References}

Abdallah M. Guar gum as corrosion inhibitor for carbon steel in sulfuric acid solutions. Port Electrochim Acta. 2004:22(2):161-75.

Abdel-Gaber AM, Abd-El Nabey BA, Sidahmed IM, El-Zayady AM, Saadawy M. Effect of temperature on inhibitive action of damsissa extract on the corrosion of steel in acidic media. Corrosion. 2006a;62(4):293-9.

Abdel-Gaber AM, Abd-El-Nabey BA, Sidahmed IM, El-Zayady AM, Saadawy M. Inhibitive action of some plant extracts on the corrosion of steel in acidic media. Corros Sci. 2006b;48(9):2765-79.

Abdel-Gaber AM, Masoud MS, Khalil EA, Shehata EE. Electrochemical study on the effect of Schiff base and its cobalt complex on the acid corrosion of steel. Corros Sci. 2009;51(12):3021-4

Abiola OK, Oforka NC, Ebenso EE, Nwinuka NM. Eco-friendly corrosion inhibitors: the inhibitive action of Delonix Regia extract for the corrosion of aluminium in acidic media. Anti-Corros Methods Mater. 2007;54(4):219-24.
Africa S. Adsorption and inhibitive properties of ethanol extracts of Musa sapientum peels as a green corrosion inhibitor for mild steel in $\mathrm{H} 2 \mathrm{SO} 4$. Afr J Pure Appl Chem. 2008:2(6):046-54.

Ajmal M, Mideen AS, Quraishi MA. 2-Hydrazino-6-methyl-benzothiazole as an effective inhibitor for the corrosion of mild steel in acidic solutions. Corros Sci. 1994;36(1):79-84

Al-Otaibi MS, Al-Mayouf AM, Khan M, Mousa AA, Al-Mazroa SA, Alkhathlan HZ. Corrosion inhibitory action of some plant extracts on the corrosion of mild steel in acidic media. Arab J Chem. 2014;7(3):340-6.

Ameh PO, Magaji L, Salihu T. Corrosion inhibition and adsorption behaviour for mild steel by Ficus glumosa gum in $\mathrm{H} 2 \mathrm{SO} 4$ solution. Afr J Pure Appl Chem. 2012;6(7):100-6.

Baboian R. Corrosion tests and standards: application and interpretation. Philadelphia: American Society for Testing and Materials; 1995. p. 197.

Belfilali I, Chetouani A, Hammouti B, Aouniti A, Louhibi S, Al-Deyab SS. Synthesis and application of 1, 7- bis (2-Hydroxy Benzamido)-4-Azaheptane an corrosion inhibitor of mild steel in molar hydrochloric acid medium. Int J Electrochem Sci. 2012;7:3997-4013.

Benabdellah M, Benkaddour M, Hammouti B, Bendahhou M, Aouniti A. Inhibition of steel corrosion in $2 \mathrm{M} \mathrm{H}_{3} \mathrm{PO}_{4}$ by artemisia oil. Appl Surf Sci. 2006;252(18): $6212-7$.

Bhaskaran R, Palaniswamy N, Rengaswamy NS, Jayachandran M. Anti-Corros Methods Mater. 2005:52:29.

Bumgartner SA, et al. Symposium on low permebility gas reservoirs. Denver: SPE/DOE 11615; 1983.

Desai PS. Azadirachita indica (neem) leaf extract used as corrosion inhibitors for mild steel in hydrochloric acid. GE Int J Engine Res. 2015;3(1):8-23.

Eddy NO, Odoemelam SA. Inhibition of the corrosion of mild steel in acidic medium by penicillin V potassium. Adv Nat Appl Sci. 2008;2(3):225-33.

Eddy NO, Ameh PO, Gwarzo MY, Okopand IJ, Dodo SN. Physicochemical study and corrosion inhibition potential of Ficus tricopoda for aluminium in acidic medium. Port Electrochim Acta. 2013;31(2):79-93.

Elachouri M, Hajij MS, Salem M, Kertit S, Aride J, Coudert R, Essassi E. Some nonionic surfactants as inhibitors of the corrosion of iron in acid chloride solutions. Corrosion. 1996;52(2):103-8.

El-Etre AY, Abdallah M, El-Tantawy ZE. Corrosion inhibition of some metals using lawsonia extract. Corros Sci. 2005;47(2):385-95.

El-Maksoud SA. Some phthalazin derivatives as non toxic corrosion inhibitors for copper in sulphuric acid. Electrochim Acta. 2004;49(24):4205-12.

Fontana MG, Greene ND. Corrosion Engineer. 1987.

Gardner DC, Eikerts JV. 58th Annual.Technical Conference. San Francisco: SPE 12028; 1983

Guendouz A, Missoum N, Chetouani A, Al-Deyab SS, Cheikhe BB, Boussalah N, Aouniti A. Quantum chemical studies on the inhibiting effect of new synthesized bipyrazols of C38 steel corrosion in $1 \mathrm{M} \mathrm{HCl}$. Int J Electrochem Sci. 2013;8:4305-27.

Kabanda MM, Ebenso EE. Density functional theory and quantitative structureactivity relationship studies of some quinoxaline derivatives as potential corrosion inhibitors for copper in acidic medium. Int J Electrochem Sci. 2012; 7:8713-33.

Kabanda MM, Shukla SK, Singh AK, Murulana LC, Ebenso EE. Electrochemical and quantum chemical studies on calmagite and fast sulphone black $F$ dyes as corrosion inhibitors for mild steel in hydrochloric medium. Int J Electrochem Sci. 2012a;7:8813-31. 
Kabanda MM, Murulana LC, Ebenso EE. Theoretical studies on phenazine and related compounds as corrosion inhibitors for mild steel in sulphuric acid medium. Int J Electrochem Sci. 2012b;7:7179-205.

Kilmartin PA, Trier L, Wright GA. Corrosion inhibition of polyaniline and poly (o-methoxyaniline) on stainless steels. Synth Met. 2002;131(1):99-109.

Kliškić M, Radošević J, Gudić S, et al. J Appl Electrochem. 2000;30:823. doi:10.1023/A:1004041530105.

Lagrenee M, Mernari B, Bouanis M, Traisnel M, Bentiss F. Study of the mechanism and inhibiting efficiency of 3, 5-bis (4-methylthiophenyl)-4H-1, 2, 4-triazole on mild steel corrosion in acidic media. Corros Sci. 2002;44(3):573-88.

Moreira RR, Soares TF, Ribeiro J. Electrochemical investigation of corrosion on AISI 316 stainless steel and AISI 1010 carbon steel: study of the behaviour of imidazole and benzimidazole as corrosion inhibitors. Adv Chem Eng Sci. 2014;4(04):503

Nishimura R. The effect of chloride ions on stress corrosion cracking of type 304 and type 316 austenitic stainless steels in sulfuric acid solution. Corros Sci. 1993;34(11):1859-68.

Obot IB, Obi-Egbedi NO. Adsorption properties and inhibition of mild steel corrosion in sulphuric acid solution by ketoconazole: experimental and theoretical investigation. Corros Sci. 2010;52(1):198-204

Obot IB, Obi-Egbedi NO, Umoren SA. Antifungal drugs as corrosion inhibitors for aluminium in $0.1 \mathrm{M} \mathrm{HCl}$. Corros Sci. 2009:51(8):1868-75.

Obot IB, Obi-Egbedi NO, Odozi NW. Acenaphtho [1, 2-b] quinoxaline as a novel corrosion inhibitor for mild steel in $0.5 \mathrm{MH}_{2} \mathrm{SO}_{4}$. Corros Sci. 2010;52(3):923-6.

Oguzie EE. Studies on the inhibitive effect of Occimum viridis extract on the acid corrosion of mild steel. Mater Chem Phys. 2006:99(2):441-6.

Oguzie EE. Corrosion inhibition of aluminium in acidic and alkaline media by Sansevieria trifasciata extract. Corros Sci. 2007:49(3):1527-39.

Petchiammal A, Deepa RP, Selvaraj S, Kalirajan K. Corrosion protection of zinc in natural sea water using Citrullus vulgaris peel as an inhibitor. Res J Chem Sci. 2012;2(4):24-34

Peter A, Obot IB, Sharma SK. Use of natural gums as green corrosion inhibitors: an overview. Int J Ind Chem. 2015;6(3):153-64.

Puri BR, Sharma IR, Pathania MS. Principles of physical chemistry. New Delhi: Shoban Jal Nagin Chand and Co; 1997.

Raja PB, Sethuraman MG. Natural products as corrosion inhibitor for metals in corrosive media—a review. Mater Lett. 2008;62(1):113-6.

Raja PB, Sethuraman MG. Inhibition of corrosion of mild steel in sulphuric acid medium by Calotropis procera. Pigm Resin Technol. 2009:38(1):33-7.

Shah SN, Walters LT. Rocky Mountain Regional Meeting. Casper: SPE12923; 1984 Ulman A. An introduction to ultrathin organic films: from Langmuir-Blodgett to Self-Assembly. 1st ed. San Diego: Academic press; 1991.

Umoren SA, Obot IB, Ebenso EE. Corrosion inhibition of aluminium using exudate gum from Pachylobus edulis in the presence of halide ions in $\mathrm{HCl}$. J Chem. 2008:5(2):355-64.

\section{Submit your manuscript to a SpringerOpen ${ }^{\circ}$ journal and benefit from:}

- Convenient online submission

- Rigorous peer review

- Immediate publication on acceptance

- Open access: articles freely available online

- High visibility within the field

- Retaining the copyright to your article 